\title{
Information Systems Impact on Nurse Call Response - Role of Velocity and Uncertainty
}

\author{
Jiban Khuntia \\ University of Colorado Denver \\ Colorado, USA \\ iiban.khuntia@ucdenver.edu \\ Mohan Tanniru \\ Oakland University \\ Michigan, USA \\ tanniru@oakland.edu \\ Fabian Fregoli \\ St. Joseph Mercy Health Systems \\ Michigan, USA \\ fabian.fregoli@stjoeshealth.org \\ Matthew Nawrocki \\ St. Joseph Mercy Health Systems \\ Michigan, USA \\ matt.nawrocki@stjoeshealth.org
}

\begin{abstract}
The nurse call system is the lifeline for a patient in a hospital room. Nurse call systems help patients initiate calls from their room in a hospital, and the response to these calls is a crucial factor in providing timely quality care and improving patient satisfaction. Two questions arise in relation to response time. Are there differences in the response to patient calls in different hospital units? Does an IT-enabled escalation of calls to ensure care quality improve the call response efficiency and effectiveness? In this study, we explore these two research questions. We argue that differences in call response time are influenced by two operational attributes of care units: velocity and uncertainty. These attributes will determine how nursing staff view both the need and urgency associated with calls and respond to them. Internet discussion forums at allnurses.com (secondary data analysis) are used to answer the first question. The analysis validates a $2 \times 2$ framework, which maps four different hospital units on velocity and uncertainty dimensions. A quantitative approach is then used to address the second question by analyzing the response time differences to patient calls by different hospital units when an IT-based escalation protocol is used. Data from 1,131 patient rooms provides evidence of response time differences in different units, each with a varying degree of velocity and uncertainty. We then discuss the implications of this research for future studies on patient satisfaction using a single metric such as nurse call response time.
\end{abstract}

Keywords: nurse call system, patient satisfaction, IS effectiveness, technology and structure fit, velocity, uncertainty 


\section{Introduction}

Hospital unit operations are complex and need a high degree of coordination, communication, and collaboration among a number of care providers, such as nurses, clinical technicians, medical assistants, and physicians (Ren et al. 2008). There are a number of different departments or units in a hospital, such as cardiac, oncology, and emergency, and each of these follows different medical practices (Alexander and Randolph 1985). For example, an emergency practice may handle patients who arrive with unexpected injuries and need immediate attention, while an oncology practice focuses on long term treatment and management of cancer patients. Hence, the resources used, care management protocols within each unit, and treatment delivery practices vary between emergency and oncology units. Each hospital unit runs like an independent entity (i.e., like a small business unit) and contributes to different unit goals and employee perceptions.

All hospital units are focused on providing quality care, and nurses and nursing staff deliver this care by acting as the "movers and shakers" or as "hostesses" of a hospital unit (Sheedy 1989). To deliver high quality care effectively with limited resources, nurses have to make quick decisions by continually prioritizing/re-prioritizing various activities in the unit, sometimes with limited information or outcome predictability (Ebright 2010). Communication and coordination through effective sharing of information is crucial (Toussaint and Coiera 2005). Information, when coming from multiple sources (people and machines), needs efficient coordination, and some of these coordination mechanisms include various call escalation rules and hospital norms (Reason 2001; Smits et al. 2009).

Nurse calling systems (i.e., automated communication using bed side control) in hospitals support coordination among nursing staff. These systems enable nurses to coordinate work among each other, as nurses have to be mobile and are often distributed across a hospital unit. Wireless phones connected to the nurse call system help staff respond to patient calls (Bardram and Bossen 2005; Prgomet et al. 2009). A number of studies highlight the importance of such systems for preventing falls and improving patient satisfaction (Tzeng 2011; Tzeng and Yin 2009a). Many of these studies have focused on understanding the reasons for patient calls and nurses' response time in handling these calls (Deitrick et al. 2006; Galinato et al. 2015; Lasiter 2014; Roszell et al. 2009). Some studies have shown that "planned nursing rounds" or visits to patient rooms can reduce patient-initiated calls (Meade et al. 2006; Torres 2007). A few other studies have explored differences in call response efficiency among rooms with different occupancy levels: single or double rooms (Deitrick et al. 2010), and across hospital wards (Digby et al. 2011). However, prior studies have not explored the relationship between hospital unit operational characteristics and call response efficiency and effectiveness, and that is the focus of this study.

The study seeks to explore two researchspecific questions. By reviewing hospital units that serve different patient populations (surgical patients, cancer patients, etc.) and how they address uncertainty (how care is to be provided) and velocity (number of different care treatment methods/protocols that have to considered), a $2 \times 2$ framework is conceptualized. This framework differentiates four hospital units on velocity and uncertainty dimensions. Text mining of secondary data from discussion forums at allnurses.com is used to give support to this framework. The time to respond to a call and attend to a patient when a nurse response system embeds a call escalation protocol is analyzed using data from 1,131 rooms spread across four units in a hospital. A quantitative approach, using secondary data and econometric analysis, is used to understand unit level differences on both time to respond to a call and time to attend 
to a patient. The study shows that there are differences in these times when calls come from different units (surgical, oncology, etc.). Given that the nurse call system escalates un-responded calls to another nurse or staff member, using a rule-based system, these escalation rules do play a mitigating role on unit staff response times. What is often not clear is how such technology interventions, often introduced to influence response time efficiency and patient satisfaction metric, address call effectiveness. Should the context of the call, such as urgency or complexity of patient care conditions, as perceived by experienced care professionals, have relevance in the way calls are responded to? If so, how might the rule based escalations incorporate this context? The organizational implications of this study, especially when nurse call response time is tied to patient satisfaction and care quality, are discussed along with directions for future research.

\section{Background and Theory}

\section{IT Enabled Nurse Call Systems}

A patient call to a nurse is a patient's lifeline in a hospital room. It is perhaps one of the few ways that a patient can control their own situation (Deitrick et al. 2006). Answering a patient's call is a communication issue that influences a patient's assessment of care quality and satisfaction (Deitrick et al. 2010). Prior work suggests that managers use patient satisfaction data to improve performance. A prompt and efficient nurse call system response is a major priority for patients and an activity that can easily be addressed (Roszell et al. 2009). Timely responses to patient calls are also important to patient safety (Digby et al. 2011). Nurse call system use rate and average call response time have been shown to impact patient satisfaction scores in acute inpatient care settings (Tzeng and Yin 2009a; Tzeng and Yin 2009b). It is equally important for the person answering the nurse call system to follow through on the patient request and to get the desired intervention so that the patient's needs are addressed in a in a timely fashion and the patient is satisfied with the service (Meade et al. 2006).

With the applications of information technology, call systems are getting highly automated and follow a set of decision rules, such as when and to whom to escalate, or when to transfer the call to nurses' wireless phone systems. Nurse call systems are used for any number of reasons (to request use of the toilet, seek pain medication, etc.), and some of these patient requests (or alerts) can be automated (as in the case of smart beds that track patient movement and send a call to a nurse). Existing research provides insights into the personal aspects of care, pointing out that nurses and patients have different perspectives about the quality of care, and this may influence the response time (Chadwick and Hearn 2014; Currie et al. 2005). Prior research suggests that different units in a hospital (in this case, the surgical unit, medical unit, and combined unit) may have different response rates to nurse call systems (Tzeng and Yin 2009b), albeit without any direct link between response rate differences and nurses' judgements. Nurse judgements on how quickly to respond to patient nurse call systems may be influenced by performance measures other than patient satisfaction, such as mortality, rapid response to address complications and code blue situations.

In this study, we use the nurse calls initiated by a patient to see how promptly the nursing staff are responding. Patient perception of prompt nurse call response is dependent not only on how quickly a call is answered, but also on the manner in which it is answered and whether basic needs are met. Patient perception and satisfaction can be positively impacted by evidence-based nursing practices, such as proactive rounding to anticipate patient needs and nurse availability at odd hours (Torres 2007). However, the automated call systems are also introducing a set of unwanted consequences in the hospital routines or a 
burden on nurses. For example, wireless nurse call systems are also associated with challenges in the nurses' daily work, such as stress, frequent interruptions, and unexpected workflow changes (Klemets and Evjemo 2014; Klemets et al. 2012; Tzeng 2010), and may create a burden or technostress (Khuntia et al. 2015). Within such a context, how nurses in different units of a hospital can be efficient in managing patient calls remains an important question for practice.

Greater uncertainty, variability, and instability in hospital units are related to the decentralization of hospital units (Leatt and Schneck 1982). To control variability in patients, hospitals develop specialized units (psychiatry, pediatrics, etc.) that house core technologies in line with the types of care needed in those units. For example, psychiatric units, characterized by uncertainty, require more reciprocal flow of information than general medical care in acute care hospitals. As in operating or treatment units, technology variability was shown to be the most important contributing factor in grouping nursing care sub-units. Technology here is operationalized in terms of instability, uncertainty, and variability (Fry and Slocum 1984; Leatt and Schneck 1981; Overton et al. 1977). Instability is most discriminant in ICU, followed by surgical, obstetrical, and medical sub-units.

Uncertainty is most significant in some cases for psychiatric care units, followed by auxiliary units (treating chronically ill or aged patients, requiring long term care). Variability refers to the number of tasks a nurse may engage in to address patient care. For example, in surgical units, the nurse call systems may call for support on any number of items (pain medication, bathroom assistance, etc.), and delays in response can have a greater impact. Schoonhoven (1981), in the study of operating rooms, and Argote (1982), in the study of emergency rooms, found significant equivocality or velocity. These units often need organizational structures that are nonstandard in order to support greater coordination and improve care quality. In fact, these non-standard and coordination supporting units are also considered crucial for changes that occur frequently (high velocity) and often need sense making and adaptation (Weick et al. 2005). Nursing staff designed to support patients in high velocity units have to deal with a wide variation in patient treatments and address unanticipated situations. The tasks they perform vary significantly, and teams associated with these tasks are often highly involved in decision making and defining tasks. Alexander and Kroposki (2001) identified three characteristics to structure coordination of nursing subunits: vertical participation, horizontal participation, and formalization. Vertical participation is the degree to which supervisors and subordinates consult together as decisions are made. Horizontal participation is the degree to which various individuals are involved with peers in decision making. In formalization, various hospital rules and procedures are used. High velocity unit teams may use a greater degree of vertical participation, while horizontal participation or peer consultation may be appropriate in situations where there is less change.

The technology and structural fit calls for differing protocols in the way a care team is coordinated. Variation in these protocols may explain when a nurse may choose to answer a call or a let a peer or supervisor (who may designate it to anyone) respond to a call. Several patient calls are largely for problems that do not require responses from registered nurses (RNs) or from licensed practical nurses (LPNs), and they can be appropriately handled by certified nursing assistants (Sheedy 1989). Van Handell and Krug (1994) categorized and quantified patients' use of nursing call lights and found that most occur at meal and medication times, when staff was busiest. This may provide opportunities for using proactive nursing rounds or even clustering nursing resources to address patient satisfaction (Meade et al. 2006). The current study is positioned in the discussions 
around unit wise clusters of nursing practices, the proactive response to patient calls, and the importance of IT in improving call response efficiency.

\section{Velocity and Uncertainty in Organizational Processes and Effects of Information Technology}

Velocity in physics refers to the rate of displacement or movement of a body or mass in a particular direction. Velocity is a vector quantity jointly defined by two distinct attributes: the rate of change and the direction of change. These changes can be observed along various components of an operational unit: inputs, process or workflows, outputs, and information used and coordination needed to support operations. The rate of change typically is the amount of change in one component over a specified period of time. The direction of change refers to a flow direction as well as discontinuity or change in trajectory. Rapid changes in environmental factors are often viewed as contributing to high velocity organizations in management literature (Bourgeois III and Eisenhardt 1988; Eisenhardt and Bourgeois 1988). High velocity here refers to the rapid changes in demand, competition and technology, so much so that information becomes inaccurate, not available or becomes absolute with the quick passing of time. Often high velocity organizations call for fast decisions, using more information, developing more alternatives, and responding quickly to dynamic and uncertain situations (Eisenhardt 1989).

Uncertainly refers to situations that involve unknown or imperfect information. Uncertainty may refer to lack of knowledge or limited knowledge in describing an existing state, a future outcome, or the number of possible outcomes (Chambers and Quiggin 2000; Gilboa 2009). Uncertainty in an organization can be manifested through a number of ways, such as the concepts in early literature on perception of various environmental factors (Duncan 1972), or in terms of state (environmental factors that affect a decision, the subsequent effects, and responses) (Milliken 1987). These conceptualizations have helped to identify uncertainty in value chains or supply chains in organizations, characterized by supply uncertainty, process uncertainty and demand uncertainty (Angkiriwang et al, 2014). Specifically related to the operations or processes, uncertainty is conceptualized as the probabilistic nature of the availability of tools and equipment (Van Kampen et al 2010), process demands and outcomes (Schmitt \& Snyder, 2012; Tang 2006), operational qualities (Wu, Blackhurst, \& O'grady, 2007) and processing times (Cao, Patterson, \& Bai, 2005). Uncertainty in internal operations may also be related to such factors as labor issues, unstable availability of working capital, and problems with information technology.

Velocity and uncertainty are two dimensions of environmental complexity that can influence an organization's operations. Dynamic consumer driven changes today lead to many internal and external unknowns, contributing to both velocity and uncertainty. To address these complexities, information technology (IT) has been used to assess the context, evaluate available options, and recommend possible best courses of action. For example, real options perspective is used to evaluate the costs and benefits of different approaches, and select future IT investments (Chulkov and Desai 2008, Tiwana et al 2006). Under high velocity or equivocal situations, information gathered may have multiple interpretations - e.g., positive or negative, biased or unbiased (Bowen 1987). A suggested solution under these circumstances is a clarification of information by higher levels of the organizational hierarchy or escalation of the situation to an appropriate decision making authority.

The concepts of velocity and uncertainty in this study are taken as two attributes for differentiating information needs of different hospital units, relating to the operational 
IS Impact on Nurse Call Response / Khuntia et al.

environmental situations. These two attributes may be also be related to the nature of the task of different units. For instance, Zinn et al. (2003) build on the structure and technology fit using a continuum of routine to non-routine technologies supported by mechanistic and organic structures. They classify practices as "cure" or "care." The cure practices are often guided by well-established knowledgebased protocols, while care practices rely on more ad hoc approaches. For example, oncology may use cure practices (treatment protocols are known but their application to individual patients vary), and surgical units use care practices (surgical knowledge, even if known, has to be dynamically adapted to each patient based on what happens during a surgery). The technological and associated differences in cure/care practices call for a fit between technology and structure (Miles et al. 1978), and such a fit is often tied to performance (Alexander and Randolph 1985). For example, units with high technological uncertainty (surgical or neurology units) may use fluid and organic structures, while units with low technological uncertainty (oncology or cardiac units) may use a rigid, bureaucratic structure. Thus, the response to a situation within the organizational structure, and in the realm of the use of a technology, depends on the fit between the environment and technology (i.e., how to respond to different information needs of different hospital units), and the tasktechnology within a unit (i.e., differentiating how technology fits to the nature of the tasks within the unit) (Goodhue \& Thompson 1995, Fuller and Denis 2009, Dennis et al. 2001).

Velocity and uncertainty can appear in many contexts within an organization, and an assessment of the context and an evaluation of options are necessary preconditions before taking any action. While IT may help in the evaluation of different scenarios using diverse sets of information, multiple interpretations and sense making is needed before a possible action plan is chosen. Managers and decision makers interpret situations differently from unclear and ambiguous information and face a dilemma in resolving the issue at hand. A conflict in such interpretations can foster disagreements on the course of action to take (Irani 2002; Smithson and Hirschheim 1998). IT in this context can be instrumental in providing access to rich information and enabling escalation for complex tasks. Prior studies indicate that the richness of communication media influences the process and outcome of the communication (Carlson and Zmud, 1999; Robert and Dennis, 2005). In complex and ambiguous task environments, richer media communication media is effective (Daft, Lengel and Trevino, 1987; Lengel and Daft, 1989). We suggest that IT escalation of the call process enables richer media for communication and the accomplishment of complex tasks, based on prior studies on how richer media helps in the review and revision of actions (Lee and Panteli, 2010), knowledge-building and learning experiences (Timmerman and Madhavapeddi, 2008), organizational communications (Watson-Manheim and Bélanger, 2007), and task execution where there is high degree of cognitive processing (Robert and Dennis, 2005). However, the ultimate decision making in these situations calls for reliance on personal experiences and judgements of the staff and managers (Bannister and Remenyi 2000).

Thus, we posit that the role of IT is not a singular or unilateral approach when there is velocity and uncertainty, but a mix of support that includes the gathering of multiple interpretations, capturing thoughts from various perspectives and experiences, generating alternatives, and incorporating judgments of staff and managers in an organization. In general, IT is a tool that helps support the gathering and analysis of diverse data and support complex decision making, using a mix of computerized and human decision makers. A number of examples illustrate how IT escalation may occur when there is velocity and uncertainty 
(see Table 1). These examples address velocity and uncertainty along four dimensions of an organizational unit's operations: input, process and workflows, output, and information communication and coordination. Velocity and uncertainty can be distinctly different in each of these dimensions in health care: inputs (arrival of patients), processes (number of tests completed or health conditions diagnosed), outputs (patients who are ready for discharge or to be sent to ICU) or communication/ coordination (choices provided to patients).

Overall, how a hospital handles velocity and uncertainty in its environment can be a differentiating factor. Although hospital units can be differentiated using many dimensions, this study focuses on differences in the way a hospital unit deals with uncertainty and velocity in its operations. For example, a nurse may be uncertain about the efficacy of new medication, but this uncertainty can be lessened with further analysis and experimentation. At the operations level, uncertainty may be a characteristic of the unit or unavoidable (e.g. uncertainty in a cancer unit may be difficult to reduce because of lack of science such as treatment of cancer cells or irrevocable side reactions of a medication), and it can be reduced by varying information provided to units. Again, these are highlighted with examples in Table 1.

\section{Differentiating Hospital Units along Velocity and Uncertainty}

The study and the subsequent empirical analysis use four units of a hospital surgical, cardiac, oncology and neurology. Discussion related to other types of hospital units or a broader generalization of these results can lead to a possible extension of this study. The cardiac and surgical unit operations are of high velocity. The activities in a cardiac unit revolve around challenges related to a cardiac arrest. Cardiac arrest happens when the heart stops pumping blood and oxygen to the organs, brain, and tissues (Roger et al. 2012). A person can be resuscitated during the first several minutes after cardiac arrest. However, as more time passes, it is less likely that the person can be revived and, even if revived, will most likely suffer brain damage. The focus of cardiac units is on saving a patient's life by restoring the heart's rhythm using procedures that involve cardio-cerebral resuscitation or other improved clinical procedures (Berg et al. 2010). The latter involves keeping the patient in a post-resuscitative care regime in the intensive care unit (Yancy et al. 2013). All these procedures and subsequent care have a sense of "urgency" and require nursing staff to move rapidly to attend to the patient and coordinate and organize the necessary resources to provide for care. Similar to the coronary care (or cardiac) units, surgery units are called into action when necessitated by experts. Some surgical episodes (e.g. elective surgeries) are mostly pre-planned, and they use multiple resources: experts, technologies and instruments, and specific devices (e.g. stent, pins for orthopedic surgery etc.). Surgical intensive care units hence operate in a high velocity environment, where the patient mix is not known and there is wide variation in the types of treatments and attention, and staffing resources (the number of experts and nurses) needed to support care coordination. 


\begin{tabular}{|c|c|c|c|}
\hline & Velocity & Uncertainty & Possible Effects of IT \\
\hline Input & $\begin{array}{l}\text { Definition: The rate and direction of change } \\
\text { in or related to the input that underlie a } \\
\text { specific operation. } \\
\text { Healthcare examples: } \\
\text { O The number of patients in specific hour } \\
\text { coming to a hospital unit } \\
\text { Change in the way a patient demands } \\
\text { attention from a nurse } \\
\text { Examples from other sectors: } \\
\text { O Speed of inventory arrival } \\
\text { O Order processing speed } \\
\text { O Staff allocation to any project at initiation }\end{array}$ & $\begin{array}{l}\text { Definition: The unpredictability related to the } \\
\text { input that underlie a specific operation. } \\
\text { Healthcare examples } \\
\circ \text { The type of patients in specific hour } \\
\text { coming to a hospital unit } \\
\circ \text { Which patient demands attention from a } \\
\text { nurse } \\
\text { Examples from other sectors: } \\
\circ \text { Unpredictability in inventory/order arrival } \\
\circ \text { Challenges in fluctuations in raw } \\
\text { material supplies }\end{array}$ & $\begin{array}{l}\text { Predict outcomes with different } \\
\text { inputs on both velocity and } \\
\text { uncertainty dimensions } \\
\text { Reduce delay and enhance } \\
\text { scheduling efficiency } \\
\text { Availability of prior information } \\
\text { can reduce unpredictability and } \\
\text { equivocality through analysis. } \\
\text { Reduce perceptional differences } \\
\text { associated with inputs and their } \\
\text { potential impact }\end{array}$ \\
\hline $\begin{array}{l}\text { Process and } \\
\text { Workflows }\end{array}$ & $\begin{array}{l}\text { Definition: The rate and direction of change } \\
\text { at process or workflow levels in an operation. } \\
\text { Healthcare examples: } \\
\text { - The number of new tests needed for a } \\
\text { patient due to comorbidity } \\
\text { A patient needing a specific MRI or CT } \\
\text { scan than what is available in the unit. } \\
\text { Examples from other sectors: } \\
\circ \text { The number of authorizations for a loan } \\
\circ \text { Customizations for a customer tailored } \\
\text { product or service }\end{array}$ & $\begin{array}{l}\text { Definition: The unpredictability at process or } \\
\text { workflow levels in operations. } \\
\text { Healthcare examples } \\
\text { - A nurse need to arrange for a procedure } \\
\text { suddenly such as a dialysis of a patient } \\
\text { in a surgery bed. } \\
\text { Trauma patient developing comatose } \\
\text { symptoms or reaction to blood } \\
\text { transfusion. } \\
\text { Examples from other sectors: } \\
\text { Invoicing system charging customers } \\
\text { differentiating on customer type or credit } \\
\text { rating } \\
\circ \text { Changes due to new product orientation, } \\
\text { or new reporting systems }\end{array}$ & $\begin{array}{l}\text { Managing workflows efficiency } \\
\text { Better coordination during } \\
\text { workflow } \\
\text { Information interfaces and } \\
\text { continuous monitoring of } \\
\text { processes and workflows } \\
\text { Task management and } \\
\text { identification of critical paths } \\
\text { On demand resource allocations } \\
\text { Change determination and } \\
\text { management }\end{array}$ \\
\hline
\end{tabular}




\begin{tabular}{|c|c|c|c|}
\hline Output & $\begin{array}{l}\text { Definition: The rate and direction of change } \\
\text { in the ability and demand for specific } \\
\text { outcomes from an operation. } \\
\text { Health care examples: } \\
\text { Number of patients need to be frequently } \\
\text { moved out of bed } \\
\text { Patients needed to be moved to ICU units } \\
\text { or other units as an outcome. } \\
\text { Examples from other sectors: } \\
\text { Change in sales in a particulate product } \\
\text { due to advertisements or seasonal } \\
\text { demands } \\
\text { Change in the product mix in response to } \\
\text { a market condition }\end{array}$ & $\begin{array}{l}\text { Definition: The unpredictability at output } \\
\text { from an operation. } \\
\text { Healthcare examples: } \\
\circ \text { Who needs to be discharged when } \\
\circ \text { Availability of beds in other units to take } \\
\text { a patient. } \\
\circ \text { Growing discharge at certain times, or } \\
\text { nature of discharge (home care vs. } \\
\text { nursing care) in a given period. } \\
\text { Examples from other sectors: } \\
\circ \text { Uncertainty in the customer orders, or } \\
\text { specifications } \\
\circ \text { Product variant and capacity } \\
\text { management in job-order production } \\
\text { processes }\end{array}$ & $\begin{array}{l}\text { Predictability of output and its } \\
\text { effect on performance, such as } \\
\text { returns, customer satisfaction, } \\
\text { and unit level effectiveness. } \\
\text { Confirmation and feedback loop } \\
\text { between output and subsequent } \\
\text { results (e.g., sales and customer } \\
\text { satisfaction linkage) } \\
\text { Updating financial and fiscal } \\
\text { numbers associated with the } \\
\text { output for immediate impact } \\
\text { assessment }\end{array}$ \\
\hline $\begin{array}{l}\text { Information } \\
\text { and } \\
\text { Coordination }\end{array}$ & $\begin{array}{l}\text { Definition: The rate and direction of change } \\
\text { in information flow and coordination that } \\
\text { affects the operations in a unit } \\
\text { Healthcare example/s: } \\
\text { The change in who informs the nurses or } \\
\text { doctors when the patient develops an } \\
\text { emergency, patient, attending staff, family } \\
\text { and friend attending the patient. } \\
\text { Change in the direction of instructions on } \\
\text { attending the patient, such as doctor to } \\
\text { nurse or specialist to nurse, or nurse to } \\
\text { doctor. } \\
\text { Examples from other sectors: } \\
\text { Consolidation or reporting of customer } \\
\text { specific sales data to provide on-the-fly } \\
\text { discounts } \\
\text { Aggregation of seasonal demand data to } \\
\text { avoid bullwhip effect for distributors }\end{array}$ & $\begin{array}{l}\text { Definition: The uncertainty or change in } \\
\text { information flow and coordination that } \\
\text { affects the operations in a unit } \\
\text { Healthcare examples: } \\
\text { O Where to find the patient's information at } \\
\text { the time of a procedure } \\
\text { Coordination of a call a family member } \\
\text { or inform the family member prior to a } \\
\text { baby's birth } \\
\text { Examples from other sectors: } \\
\text { Recommendation systems informing } \\
\text { and determining customer choice of } \\
\text { products } \\
\text { Flow of both customer and partners' } \\
\text { information in clearing houses } \\
\text { Stock return prediction due to product } \\
\text { portfolios }\end{array}$ & $\begin{array}{l}\text { Efficient peripheral service and } \\
\text { product delivery due to } \\
\text { information availability } \\
\text { Assessment of customer } \\
\text { preferences using information } \\
\text { and analytics } \\
\text { Enhancing inter-departmental or } \\
\text { inter-partner information sharing } \\
\text { and flow } \\
\text { Effective and efficiency } \\
\text { enhancements in : } \\
\circ \text { User need identification } \\
\circ \text { Change determination } \\
\circ \text { Exchange and relationships } \\
\circ \text { Planning and strategy } \\
\text { formulation }\end{array}$ \\
\hline
\end{tabular}


In contrast to the surgical and cardiac units, oncology and neurology units use a set of operations that are more "touchy" than "speedy". Oncology units deal with cancer patients and use specialized radiation procedures to destroy cancer cells using high-energy radiation or other particles. Medical procedures that treat cancer use chemotherapy to remove tumors and surrounding tissues, perform biopsy surgeries, or engage in palliative care for patients with terminal malignancies (Deng et al. 2009). Activities in oncology units include explaining the diagnosis (where the cancer is located and the degree of its spread to other parts of the body) to the patient, discussing treatment options, making recommendation for high-quality and compassionate care, and managing pain and side effects such as constipation, nausea, vomiting, and fatigue (Frenkel et al. 2010). The challenge in oncology is to provide effective and compassionate care (e.g. high touch), and speed is not necessary.

Neurology is similar in many ways to oncology. It is the specialty related to the diagnosis and treatment of nervous system disorders of the brain, the spinal cord, and various nerves. The diagnosis and treatment of such disorders cover the central and peripheral nervous system (and its subdivisions: the autonomic and the somatic nervous systems), including blood vessels and all effector tissue such as muscle (Agid 2000). Neurological practice relies heavily on the field of neuroscience (Koroshetz and Landis 2014). Neurology unit teams are trained to investigate, diagnose and treat neurological disorders, mostly without any surgery (excluding neurosurgery). Neurology units treat patients with a number of disorders, including headaches, strokes, seizures, multiple sclerosis, dystonia, muscular dystrophy, peripheral nerve disease, learning disorders, Parkinson's, Huntington's, and Alzheimer's disease (Stüve 2012). Some are also engaged in neurological rehabilitation. Many neurological problems are characterized by pain and can be chronic, debilitating and difficult to treat. A large portion of the neurology practice is consultative and has close links to psychiatry. The activities in neurology units do not involve speed, but require a high level of effective understanding of patients and their mental conditions or issues that surface. The neurology unit is low velocity but calls for care practices connected to the patient's operating condition.

With regard to uncertainty, surgical units use an established plan that describes both operative processes in a surgical unit and post-operative processes subsequent to a surgery. Each surgical procedure may include temporary immobility or unconsciousness with anesthesia, exploration of the issue involved, repairing the body part, closing the part for further healing, and bringing the patient to consciousness with post-operative care. The procedural requirements and associated dynamics on the unit floor are of low uncertainty as everyone knows what is needed and when, and the path a patient takes at each step. Cardiac units, however, exhibit a high degree of uncertainty.

The cardiac patient needs close monitoring and support from special equipment and medications from highly trained doctors and nurses who specialize in continual care. Cardiac units often have high staff-to-patient ratios and access to advanced medical resources. Patient may include diagnosis using electro-cardiogram machines, imaging, stress tests, etc., and patients may engage in therapeutic treatments such as angiogenesis or specialized surgical procedures such as coronary artery bypass or stent placement procedures. The time some of these procedures take and activities to complete these procedures have many unknown factors and are difficult to predict. For example, the effectiveness of a stent or a bypass has a high degree of uncertainty, along with a high velocity in the operational environment. 
Neurology and oncology units differ in the uncertainty dimensions as well. Neurological conditions are far from death situations. A patient suffering from a seizure or Alzheimer's disease will not die in an instant if care is not available, and the path of disease progression and side-effects of treatments will not lead to catastrophic conditions (e.g. unconsciousness). Therefore, the operational characteristic of a neurology unit is a stable and guided path of care management and maintenance. On the contrary, the oncology unit patient situations can be unpredictable. For instance, a patient undergoing chemotherapy may progress to a hyper sensitive condition that is not anticipated, contribute to kidney disorders, immediate anemic conditions, or transfusion reactions. The symptoms may at times lead to a worsening condition instantly, in contrast to neurological patients. This characterizes an oncology unit as a highly uncertain environment.

In summary, the situational interpretation of the different units discussed above places them in four distinct quadrants of the velocity and uncertainty framework (see Figure 1). The practice and characteristic differences of each of these units lead us to conclude that surgery and cardiac units are of high velocity, while neurology and oncology are of low velocity. Also, the uncertainty associated with cardiac and oncology practices is high compared to surgery and neurology practices.

$$
\begin{aligned}
& \begin{array}{l|l}
\text { High High Velocity, Low Uncertainty } & \text { High Velocity, High Uncertainty }
\end{array}
\end{aligned}
$$

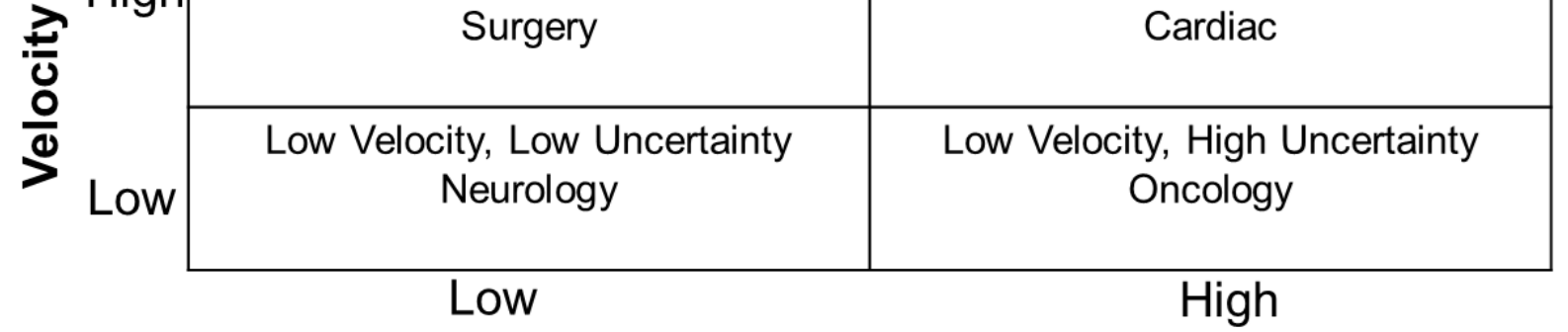

$$
\begin{aligned}
& \text { Uncertainty }
\end{aligned}
$$

\section{Figure 1 - The Situational Interpretation of Hospital Units}

\section{Hospital Unit Differentiation and Response to Nurse Calls}

The practice guidelines associated with each operational unit influence the sensemaking behavior of the nursing staff who respond to a call coming from these units (Weick et al. 2005). Nursing staff designated to support patients in high velocity units have to deal with a wide variation in patient treatments and must address unanticipated situations. The tasks they perform vary significantly, and teams associated with these tasks make decisions and define/redefine tasks. Their interpretation of the situation and the activities they may perform will play a role in deciding how quickly they respond. An awareness of the situation and which unit the call came from will determine whether, for example, a call is responded to by phone, or by nurses running to the patient room to attend to the patient. The phone response (referred to here as "response") assumes a general awareness of what is going on and may allow for a solution over the phone itself. However, in the case of situations that demand taking care of a patient immediately or addressing some critical issues, the nurse may have to attend to the patient in the room (referred to here as "concerned response"). 
IS Impact on Nurse Call Response / Khuntia et al.

The response or concerned response decision is based on situational awareness and an interpretation of the velocity and uncertainty associated with each operational unit environment. Situational awareness is "the perception of various elements of the environment within a volume of time and space" (Endsley 1995) and how this understanding, knowledge and context for one's own activities leads to a projection of consequential outcomes in the near future (Flin et al. 2008; Schmidt 2002). A nurse's work is to understand the situation, make sense of it, and align and integrate it with other interdependent activities in providing care delivery. Nurses also need to monitor their colleagues' activities while simultaneously making transparent their own activities, all embedded in situational sense-making leading to a "response" or "concerned response." When technology is used to support the nurse response to a patient call, four factors influence the response dynamics (phone response to concerned response). There include: (1) system use, (2) complexities within the situation and context, (3) interruptions, and (4) patient-oriented challenges.

"System use" refers to the degree to which a nurse uses a wireless phone or lets the nurse call system support the department activity. For example, a call to a nurse from any patients in a surgery unit is of high priority or that is what is understood by all nurses in the unit. Therefore, nurses would always carry phones and be on the "alert" for these calls with a collective responsibility to attend to them. However, in a neurology or oncology unit, nurses follow certain procedures such as using sterile clothes or sanitized instruments prior to entering a room. They may not carry wireless phones, or they are not easily accessible, and they may instead rely on the central location of the nurse call system to attend to the calls. In other words, the concerned response to a call may be a bit longer, as they may have to defer the call until they are ready to enter the room following the sanitized procedure.
In terms of the complexities of the context, nurses often are busy doing many different things, and attending another patient's call may not be viewed as urgent enough to abort or interrupt their current activity. Again, this determination is based on a number of factors, such as the procedural requirements for attending to a current patient, and nurses need to make just-intime decisions. For example, a nurse in the middle of changing a wound or busy inserting a venous catheter cannot take a call. These situations demand escalation of the call to the next available person. Even with escalation, the complexity of the situation in a unit could lead to a situation where many nurses do not respond to a call, leading to a "lag" in response time.

Interruptions can also contribute to response variability. For example, a nurse changing a wound has the option to leave the patient to take the call or continue with the present activity. Leaving the existing patient may lead to a bad situation. Even the thought that another patient needs this nurse at the same time can be a psychological disruption to the nurse's current work. Often repeated calls may be so disrupting that a nurse may keep the "phone away" while doing a lengthy procedure.

The "patient oriented factors" include information such as who is calling, why they are calling, and if the call is from an assigned patient or not. When a nurse is expecting a call from a specific room, the call will be answered quickly. During a shift, each nurse is assigned to one or several patients, and they are their primary responsibility. Nurses would be more willing or proactive in taking calls from these patients than a call coming from other patients. These may get ignored or passed on until the primary nurse is available. Often a situation demands that the nurse decide whether or not to leave a patient to attend to a serious primary patient.

To summarize, nurses face a number of challenges that influence the time taken to 
respond to a call. The prevailing norms of system use, situational complexities, the nurses' interpretation of the situation at hand, and patient-related factors all play important roles in addressing a call from a patient. These observations lead to the two following propositions:

Proposition P1a. The normal response time to nurse calls increases with increasing operational velocity.

Proposition P1b. The concerned response time to nurse calls decreases with increasing operational uncertainty.

\section{IT-based Escalation for Nurse Calls}

The escalation of a call based on a certain logic or rule is a recent feature in many nursing call systems. IT-based escalation can influence the response or concerned response to a patient call, and it can be influenced by the system use, complexities, interruptions and patient orientation factors. The research question is: How does an ITbased escalation effect the response and concerned response times?

IT-based escalation will increase the response time, but it will decrease the concerned response time for two reasons. First, IT-based escalation supports mobility and enhances the availability of not only the primary nurse, but also other nurses who can take the call based on the prior set heuristics. However, the time taken to respond to a call with the escalation means that the calls must first be referred to the primary nurse in the unit. If the nurse does not take the call within a number of rings, then the call gets escalated, which means it would take more time before responding to a call. Second, IT-based escalation may not be able to translate the urgency of the call to post-escalation nurses. The primary nurse knows the situation of a patient. If the primary nurse is not able to respond, the escalation then gets forwarded to an available nurse in the unit. In this scenario, the other nurses may not have a clear understanding of the patient's condition or the urgency of the call. Unless the patient is clear about the urgency cues, any other nurse would probably take a delayed approach to attend a patient, maybe after attending to the patient the nurse is currently attending.

Although IT-based escalation increases response time and decreases concerned response time to patient calls, these effects will also vary from unit to unit. Two scenarios emerge. First, implementation of a nurse call system may increase the awareness and interaction of activities within the unit. This applies more to situations of low velocity in unit operations. Nurses have free time and plan actions in such environments. For example, a nurse may check a priori who is available in nearby rooms to take a call when he or she is busy with a patient, and thus, are available to take calls with or without escalation. The nurses in the units then become aware of the activities of colleagues, increase social interactions, and improve the social presence and situational interpretation of the activities through these interactions. In such a scenario, the escalation process leads the nurses to set a pre-planned set of sense making to attend the patients efficiently with escalation. In other words, although escalation happens, it is within the unit, and the nurses are proactive in attending to the patient. In such scenarios, the IT-based escalation may decrease the response time, rather than increasing it in units such as in neurology (low velocity units). However, with low velocity and when uncertainty is high, irrespective of call response times the nurses may have a shared understanding of the urgency of the patients. As a result, with escalation, the nurses may really run fast to attend to a patient, all worried that the patient is in an urgent situation. This is the case with oncology units (low velocity unit and high uncertainty). Here, IT-based escalation will decrease the concerned response time. Similarly, although neurology is a low uncertainty unit, escalated calls may be considered to be urgent situations and may lead to the other 
IS Impact on Nurse Call Response / Khuntia et al.

available nurses (not the primary nurse who knows the patient) to pay closer attention.

The second scenario is when the units have high velocity operations. High velocity operation units demand that nurses be trained to handle things urgently, and this shared understanding will lead nurses to derive a collective responsibility when the calls get escalated. In the context of this study, both surgery and cardiac units have high velocity operations and train nurses to take escalated calls to attend immediately to pacify any urgency, irrespective of any uncertainty in their operations. Thus, we expect that although nurses are extremely busy, the high velocity nature of their operations make them collectively responsible to respond to escalated calls with a sense of urgency.

To summarize our arguments, we posit that IT-based escalation results in an increased response time in many of these units, and a decreases concerned response time. However, variation in the response time and concerned response time may depend on the situational interpretation of whether the call is urgent or not, whether nurses understand the urgency and whether the operational units have trained the nurses with any interpretative scheme. The following propositions are used to explore the unit-based variation empirically.

Proposition P2a. IT-based escalation increases the response time to nurse calls.

Proposition P2b. IT-based escalation decreases the concerned response time to nurse calls.

Proposition P2c. The moderating influence of IT-based escalation on response and concerned response times will vary across units.

We present the empirical research framework and the propositions in Figure 2.

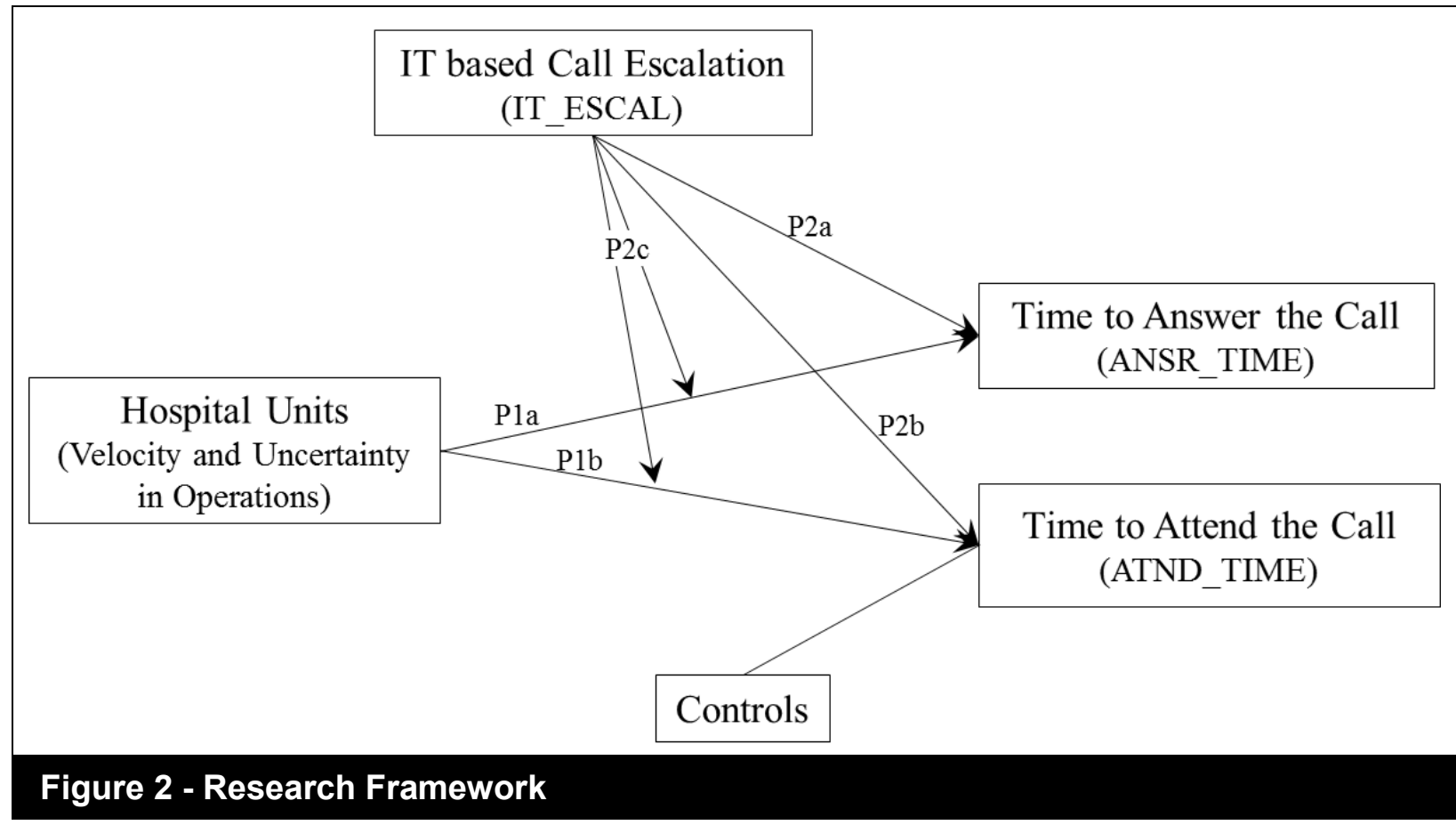




\section{Methodology}

The method for this study includes: (1) a secondary observational data and text mining/interpretation approach to validate the velocity and uncertainty differentiation of hospital units, (2) a quantitative study with data collected from the a hospital and analyzed using econometric methods to explore the response variations across four units in the hospital. We elaborate on our methodology further.

\section{Validation of Velocity and Uncertainty Differentiation of Hospital Units}

The first method is used to validate the placement of the four units in the study in the $2 \times 2$ framework along velocity and uncertainty dimensions. We used publicly available data on a leading nurse networking site allnurses.com to understand the unit differences. The site uses nurse community discussion forums to surface their issues, challenges, and solutions to understand work practices. Nurses at different levels of practice with varying experience share knowledge and seek answers to questions, engage in lively debates, and share articles, nursing jobs, degree program information, and other nursing practices in different hospital unit operations.

Three qualified researchers (two graduate level students and a faculty member) scanned through the discussion forums at allnurses.com on the four practices discussed in the study. They collected reviews and discussions related to velocity and uncertainty words embedded within the discussion texts. In each specialization category, there are around 20-25 discussions or comments. Within these comments, the researchers individually collected quotes for each unit that discussed any identifier word relevant to the velocity and uncertainty dimensions. Even with a limited number, we collected five comments in each practice category related to velocity or uncertainty. By collating individual comments, we classified the quotes and their meanings into velocity and uncertainty dimensions. Any conflicts or ambiguities were clarified with discussion amongst the three researchers. The quotes, identifier words and classification of the unit based on these words are shown in Table A1 of Appendix A. The analysis of these comments provide general support for the 2 $\times 2$ matrix of velocity and uncertainty differentiation among Surgery, Cardiac, Neurology and Oncology units.

\section{Quantitative Study and Empirical Analysis}

Patient nurse call system requests were recorded for 1,131 patient room days at SJMO captured from the ICS system between January 2015 and June 2015. A data set was prepared that included roomwise call answering data, such as: (1) the type of requests (bath or shower calls, normal calls for medication or other assistance), (2) whether the calls were escalated or not, (3) the time taken to attend the call, and (4) the time taken for someone to enter the patient room after call initiation.

The times to respond to these nurse calls have two dependent variables. The first dependent variable is the time between the patients' calls and someone talking to the patient through the phone (ANSR_TIME), i.e. the normal response time to a nurse call. The second dependent variable is the time to attend the patient (ATND_TIME), measured as the average number of minutes between the patients' call and a nurse or staff entering the patient room to serve the patient. This is referred to as the "concerned response" to a patient call as the nurse or staff rush to help the patient to address the issue. Both these variables are adjusted by the number of patients per day. The ANSR_TIME is distinct from the ATND_TIME in that answering the patient over the phone does not necessarily involve providing physical help or support to the patient. Thus, we consider ANSR_TIME as the indicator for a normal response and 
IS Impact on Nurse Call Response / Khuntia et al.

ATND_TIME as the indicator for concerned response.

The primary explanatory variable here is the IT-based call escalation (IT_ESCAL) from the room. It measures the percentage of calls escalated using the IT-based systems, routed through various escalation protocols. As shown in Figures B2-B4, although there are three different ways a call coming from a patient is responded to, common across all of these is the escalation protocol, IT_ESCAL, measured for this study. We control for total calls, average length of stay of patients, and the type of call in the models. We include dummy variables to reflect the four units which are the focus of this study, and interact the dummies with the IT_ESCAL variable to interpret the differences in response to the IT-based escalation on dependent variables across the different units.

Table 2 provides a description of variables used for the analysis. Table 3 presents descriptive statistics. The average call attending time (ATND_TIME) in our sample is 2.59 minutes, while the answering time (ANSR_TIME) is 1.32 minutes. On average, there are 383 calls placed from a room, with a maximum of 2,168 calls from any room during the study period.

\section{Table 2 - Description of Variables}

\begin{tabular}{|l|l|l|}
\hline $\begin{array}{l}\text { Name of Variable } \\
\begin{array}{l}\text { Time to Attend the Call } \\
\text { (ATND_TIME) }\end{array}\end{array}$ & $\begin{array}{l}\text { Room wise average minutes between the patients' call and } \\
\text { someone entering the patient room to serve the patient } \\
\text { (concerned response). }\end{array}$ & Type \\
\hline $\begin{array}{l}\text { Time to Answer the } \\
\text { Call (ANSR_TIME) }\end{array}$ & $\begin{array}{l}\text { Room wise average minutes between the patients' call and } \\
\text { someone talking to the patient through phone (response). }\end{array}$ & Continuous \\
\hline $\begin{array}{l}\text { IT based Call } \\
\text { Escalation (IT_ESCAL) }\end{array}$ & $\begin{array}{l}\text { Percentage of calls escalated out of the total calls placed from the } \\
\text { room }\end{array}$ & Continuous \\
\hline TOT_CALL & Total calls placed from the room & Continuous \\
\hline Surgery & Rooms in Surgical unit & Binary/dummy \\
\hline Cardiac & Rooms in Cardiac unit & Binary/dummy \\
\hline Oncology & Rooms in Oncology unit & Binary/dummy \\
\hline Neurology & Rooms in Neurology unit & Binary/dummy \\
\hline Shower Call & The call origination is during the shower or bath area & Continuous \\
\hline LOS & Average length of stay of patients in the room & \\
\hline
\end{tabular}

\begin{tabular}{|l|l|l|l|l|l|}
\hline Table 3 - Descriptive Statistics & \multicolumn{3}{l|}{} \\
\hline Variables & Obs & Mean & SD & Min & Max \\
\hline ATND_TIME & 1131 & 2.59 & 1.48 & 0.00 & 12.42 \\
\hline ANSR_TIME & 1131 & 1.32 & 0.86 & 0.00 & 9.82 \\
\hline ESCA & 1131 & 0.34 & 0.06 & 0.00 & 0.58 \\
\hline TOT_CALL & 1131 & 384 & 584 & 1.00 & 2168 \\
\hline Surgery & 1131 & 0.26 & 0.37 & 0.00 & 1.00 \\
\hline Cardiac & 1131 & 0.20 & 0.30 & 0.00 & 1.00 \\
\hline Oncology & 1131 & 0.23 & 0.30 & 0.00 & 1.00 \\
\hline Neurology & 1131 & 0.31 & 0.20 & 0.00 & 1.00 \\
\hline Shower Call & 1131 & 0.24 & 0.43 & 0.00 & 1.00 \\
\hline
\end{tabular}


For the empirical analysis to study the influence across units, we specify a standard cross-sectional model of the form,

$$
Y_{i}=X_{i} \beta+\varepsilon_{i}
$$

where $Y$ represents outcome variables such as time to answer the patient and time to respond to the call by entering into the patient room; $X$ represents a vector of factors, such as room and type of unit, and IT-enabled escalation of the calls; $\beta$ is a vector of parameters to be estimated, and $\varepsilon$ is the error term associated with each observation $i$.

We conducted two sets of analysis. First, we estimated the direct effects of the call types and unit effects on answer time and attend time. Second, the interaction effects of the IT escalation and unit type on the answer and attend times were explored. The set of equations corresponding to two sets of analysis are specified. The specifications for direct effect models are:

ANSR_TIME $=\beta_{10}+\beta_{11}$ IT_ESCAL $+\beta_{12}$
Shower Call $+\beta_{13}$ Cardiac $+\beta_{14}$ Surgery
$+\beta_{15}$ Oncology $+\beta_{16}$ Neurology +
Control $_{1 c}+\varepsilon_{1}$
ATND_TIME $=\beta_{20}+\beta_{21} I T$ IT ESCAL $+\beta_{22}$
Shower Call $+\beta_{23}$ Cardiac $+\beta_{24}$ Surgery
$+\beta_{25}$ Oncology $+\beta_{26}$ Neurology +
Control $_{2 c}+\varepsilon_{2}$

The empirical model is to test the interaction models as specified:

$$
\begin{aligned}
& \text { ANSR TIME }=\beta_{30}+\beta_{31} \text { IT ESCAL }+ \\
& \beta_{32} \quad \bar{T} \text { ESCAL } \times \text { CardiaC }+\beta_{33} \\
& \text { IT_ESCAL } \times \text { Surgery }+\beta_{34} \text { IT_ESCAL } \times \\
& \text { Oncology }+\beta_{35} \text { IT_ESCAL } \times \overline{\text { Neurology }} \\
& +\beta_{3 c} \text { Control }_{3 c}+\varepsilon_{3} \\
& \text { ATND_TIME }=\beta_{40}+\beta_{41} \text { IT_ESCAL }+ \\
& \beta_{42} \quad \overline{T T} E S C A L \times{ }_{\text {Cardiac }}+\beta_{43} \\
& \text { IT_ESCAL } \times \text { Surgery }+\beta_{44} I T+E S C A L \times \\
& \text { Oncology }+\beta_{45} \text { IT_ESCAL } \times \overline{\text { Neurology }} \\
& +\beta_{4 c} \text { Control }_{4 c}+\varepsilon_{24}
\end{aligned}
$$

\section{Results of the Empirical Analysis}

Table 4 provides parameter estimates of the direct effect models. Column 1 of Table 4 reports results of equation 1 relevant to the normal response time to the nurse calls. We find that a call originating from Cardiac has a negative and significant association $(\beta=$ -0.287, $p<0.05)$ with response time (ANSR_TIME). Similarly, for Surgery the coefficient is negative and significant $(\beta=$ $-0.513, p<0.01)$, as well as for Oncology $(\beta$ $=-0.052, \quad p<0.1)$. The coefficient comparison tests yields significance at $p=0.01$ levels, with the calls from Surgery having the highest effect, followed by Cardiac and Oncology calls. In addition, we find that the Neurology calls have a positive and significant result on response time $(\beta=$ $-0.549, p<0.01)$ indicating that Neurology calls are responded to somewhat late compared to other units' calls. As we argue in the theory development section, Surgery and Cardiac are high velocity environments but Neurology and Oncology are low velocity environments. Our results show that Neurology and Oncology have higher response times than Cardiac and Surgery; thereby supporting proposition P1a.

Column 2 of Table 4 presents the results of equation 2 that is related to the concerned response time to the nurse calls. We find that a call originating from Cardiac has a negative and significant association $(\beta=$ -0.486, $p<0.01$ ) with concerned response time (ATND_TIME). However, the coefficients are positive and significant for Surgery $\beta=0.053, p<0.05)$, Oncology $(\beta=$ $0.123, p<0.01)$, and Neurology $(\beta=0.374$, $p<0.01)$. The coefficient comparison tests yields significance at $p=0.05$ levels. Recall that we argued that concerned call response times are negatively correlated with the uncertainty in the units, i.e., the higher the uncertainty, the faster a nurse would plausibly try to attend a patient's call by visiting the room. 


\begin{tabular}{|c|c|c|c|}
\hline VARIABLES & $\begin{array}{c}\text { (1) } \\
\text { ANSR TIME }\end{array}$ & $\begin{array}{c}(2) \\
\text { ATND TIME }\end{array}$ & Interpretation of the results \\
\hline Cardiac & $\begin{array}{l}-0.287^{\star \star} \\
(0.148)\end{array}$ & $\begin{array}{l}-0.486^{\star * *} \\
(0.080)\end{array}$ & $\begin{array}{l}\text { Cardiac unit answers nurse calls promptly and attends } \\
\text { to promptly (fast response, high concern). }\end{array}$ \\
\hline Surgery & $\begin{array}{l}-0.513^{* * *} \\
(0.127)\end{array}$ & $\begin{array}{l}0.053^{* *} \\
(0.018)\end{array}$ & $\begin{array}{l}\text { Surgery unit answers nurse calls promptly (fast } \\
\text { response), but somewhat slow in attending (moderate } \\
\text { concern). }\end{array}$ \\
\hline Oncology & $\begin{array}{l}-0.052^{*} \\
(0.041)\end{array}$ & $\begin{array}{l}0.123^{* * *} \\
(0.082)\end{array}$ & $\begin{array}{l}\text { Oncology unit answers nurse calls somewhat promptly } \\
\text { (moderate response), but quite slow in attending the } \\
\text { calls (moderate concern). }\end{array}$ \\
\hline Neurology & $\begin{array}{l}0.549^{* * *} \\
(0.191)\end{array}$ & $\begin{array}{l}0.374^{* * *} \\
(0.103)\end{array}$ & $\begin{array}{l}\text { Neurology unit does not answer patient calls promptly } \\
\text { (slow response), and very slow in attending the calls } \\
\text { (least concern). }\end{array}$ \\
\hline IT_ESCAL & $\begin{array}{l}0.091^{\star * *} \\
(0.029)\end{array}$ & $\begin{array}{l}-0.416^{\star \star \star} \\
(0.070)\end{array}$ & $\begin{array}{l}\text { Escalation increases response time, but decreases } \\
\text { concerned response time. }\end{array}$ \\
\hline Shower Call & $\begin{array}{l}-0.434^{* * *} \\
(0.231)\end{array}$ & $\begin{array}{l}-0.427^{* * *} \\
(0.125)\end{array}$ & \\
\hline Constant & $\begin{array}{l}3.150^{\star * *} \\
(0.221)\end{array}$ & $\begin{array}{l}0.716^{* * *} \\
(0.119)\end{array}$ & \\
\hline Observations & 1131 & 1131 & \\
\hline R-squared & 0.311 & 0.401 & \\
\hline \multicolumn{4}{|c|}{$\begin{array}{l}\text { Standard errors in parentheses } \\
* * *\end{array}$} \\
\hline
\end{tabular}

Because Surgery and Neurology are low uncertainty environments related to Cardiac and Oncology units, the concerned response time in the earlier units should be more than the later wards. Our results partially support that, as we find that Neurology has the highest concerned response time, while Cardiac has the fastest concerned response time. For Surgery and Oncology, there is a slight difference showing Oncology has a higher concerned response time than Surgery-somewhat opposite to our proposed directions. Thus, we find partial support for proposition $\mathrm{P} 1 \mathrm{~b}$.

Table 4 also shows that IT_ESCAL is positive and significant on ANSR_TIME $(\beta=$ $0.091, \quad p<0.01)$. This result supports proposition $\mathrm{P} 2 \mathrm{a}$. In addition, we also find that IT_ESCAL is negative and significant on ATND_TIME $(\beta=-0.416, p<0.01)$. This result supports proposition $P 2 b$.

Table 5 presents the interaction effect models, with Column 1 of Table 5 reporting the results of equation 3 , and Column 2 reporting the results of equation 4 . We find that the interaction term Cardiac $X$ IT_ESCAL is positive and significant on ANSR_TIME $(\beta=0.055, \quad p<0.05)$ and negative and significant on ATND_TIME $(\beta$ $=-0.094, p<0.01)$. In other words, IT-based escalation increases the response time in the Cardiac unit, but decreases the concerned response time which necessitates rushing to the patient room. Second, we find that the interaction term Surgery $X$ IT_ESCAL is positive and significant on ANSR_TIME $(\beta=0.075$, $p<0.05)$ and negative and significant ATND_TIME $(\beta=-0.221, p<0.05)$. IT-based escalation increases the response time, but decreases the concerned response time in the Surgery unit. Third, for the Oncology unit, the results of interaction shows positive and significant effects for ANSR_TIME $(\beta=$ $0.273, p<0.01$ ), but no significant effect for ATND_TIME. These results indicate that although escalation in Oncology increases the response time, it has no effect on the concerned response time. Finally, we find 
that the interaction term Neurology $X$ IT_ESCAL is negative and significant both on ANSR_TIME $(\beta=-0.187, p<0.05)$ and ATND_TIME $(\beta=-0.391, \quad p<0.05)$, indicating that the IT-based escalation has a mitigating impact on both response and concerned response times for the calls in a Neurology unit. These results largely support the proposition $P 2 c$ that the moderating influence of IT-based escalation on response and concerned response times will vary across units.

\begin{tabular}{|c|c|c|c|}
\hline & $(1)$ & $(2)$ & \multirow{2}{*}{ Interpretation of the results } \\
\hline VARIABLES & ANSR_TIME & ATND_TIME & \\
\hline $\begin{array}{l}\text { Cardiac } \times \\
\text { IT_ESCAL }\end{array}$ & $\begin{array}{l}0.055^{* *} \\
(0.091)\end{array}$ & $\begin{array}{l}-0.094^{* * *} \\
(0.016)\end{array}$ & $\begin{array}{l}\text { IT based escalation in Cardiac increases response time, } \\
\text { but decreases concerned response time. }\end{array}$ \\
\hline $\begin{array}{l}\text { Surgery } \times \\
\text { IT_ESCAL }\end{array}$ & $\begin{array}{l}0.075^{\star *} \\
(0.031)\end{array}$ & $\begin{array}{l}-0.221^{* *} \\
(0.011)\end{array}$ & $\begin{array}{l}\text { IT based escalation in Surgery increases response time, } \\
\text { but decreases concerned response time. }\end{array}$ \\
\hline $\begin{array}{l}\text { Oncology } x \\
\text { IT_ESCAL }\end{array}$ & $\begin{array}{l}0.273^{* * *} \\
(0.194)\end{array}$ & $\begin{array}{l}0.054 \\
(0.022)\end{array}$ & $\begin{array}{l}\text { IT based escalation in Oncology increases response time } \\
\text { but no effect on concerned response time. }\end{array}$ \\
\hline $\begin{array}{l}\text { Neurology } x \\
\text { IT ESCAL }\end{array}$ & $\begin{array}{l}-0.187^{* * *} \\
(0.104)\end{array}$ & $\begin{array}{l}-0.391^{* * *} \\
(0.120)\end{array}$ & $\begin{array}{l}\text { IT based escalation in Neuro decreases response time, } \\
\text { but also decreases concerned response time. }\end{array}$ \\
\hline \multicolumn{4}{|c|}{$\begin{array}{l}\text { Standard errors in parentheses } \\
{ }^{* * *} p<0.01,{ }^{* *} p<0.05,{ }^{*} p<0.1 \\
\text { Models include direct effects, control variables and a constant term. These details are omitted for brevity }\end{array}$} \\
\hline
\end{tabular}

\section{Robustness and Validation Checks}

Several robustness checks were done to check for the validity of the results. The data was tested for multi-collinearity by computing variance inflation factors (VIF). The VIFs in the models were less than 6, indicating that multi-collinearity is not a serious concern in the data. Second, the data was mean-centered for explanatory variables to help facilitate interpretation of the results. Results from models with meancentered values are similar to results from models with non-standardized values. Third, both the answer and respond times are somewhat censored in the beginning or towards the maximum value. Mostly nurses and nursing staff attend to the calls as soon as possible, i.e., within the golden two or three minutes after the call is placed. In addition, attending a call after 12 or 15 minutes is not useful, as the patient may have initiated another call and canceled their original call. To account for the early and late censoring of the calls, a doublecensored Tobit maximum likelihood estimation was used to account for double censoring of the dependent variables ATND_TIME and ANSR_TIME; accounting for the left censoring at 0 , and right censoring around the maximum values of the dependent variables. The results of the Tobit models are similar with slight variation of the significance levels.

Finally, a second issue in our data is what happens to the calls that are lost due to either technical issues or other reasons they are not attended to. Since our analysis captures information about the calls that were attended or answered, there is an inherent survival bias in the data. We conducted additional analysis to address survival bias in our models (that if many calls are either not answered or answered too late, leading to censoring of the data), by estimating the models using a truncated regression approach (see Pg. 863, Greene 2008). This approach assumes a truncated distribution of the dependent variable as a part of the un-truncated distribution that is above or below some specified value (i.e., for the survived calls under consideration). The results of the truncated regression 
IS Impact on Nurse Call Response / Khuntia et al.

models are also similar to our main estimation models, indicating the validity of our results.

\section{Discussion}

\section{Findings}

The goal of this study is to understand how hospital units differed in their response to patient nurse call systems. It is argued that hospital units differ in the velocity and uncertainty dimensions embedded in the operating practices of various units. This argument is validated using secondary data from allnurses.com discussion forums, and a $2 \times 2$ matrix was presented, differentiating four units in a hospital along velocity and uncertainty dimensions. The subsequent response and concerned response attributed to the nurse calls is validated using response patterns in these units based on secondary data and analysis from four units at SJMO hospital. Finally, the ITbased escalation of the nurse calls is proposed to have a moderating effect on the unit-based practices on both answer time and attend time for nurse calls. Using a response and concerned response framework, the direct and moderating impact of IT-based escalation was empirically investigated using call response data from 1,131 rooms from four units of the SJMO hospital.

The findings from this analysis suggest that calls from Cardiac, Surgery and Oncology are answered promptly, but not in case of Neurology. Also, in Surgery, Oncology and Neurology units the coefficients are positive and significant, but negative and significant for the Cardiac unit. Furthermore, the ITbased escalation increases the response times in the Cardiac, Surgery and Oncology units, but decreases the response time in the Neurology unit. This means that the Cardiac unit is highly concerned in attending the calls, compared to other units. However, the values of the coefficients indicate that the Neurology unit shows the least concern in attending nurse calls, followed by Oncology and Surgery. Regarding the attending time, the findings show that ITbased escalation decreases the concerned response times in the Cardiac, Surgery and Neurology units. In summary, there is support for the proposition that IT-based escalation has a mitigating effect, albeit differently in different hospital units. Based on the suggestions the situational interpretation and contextual differences are not only inherent in the operations, but are reflected in the nurse response to patient needs through call bells (see Figure 3 ), we populate the previous $2 \times 2$ framework along velocity and uncertainty

\begin{tabular}{|c|c|c|}
\hline \multirow{3}{*}{ 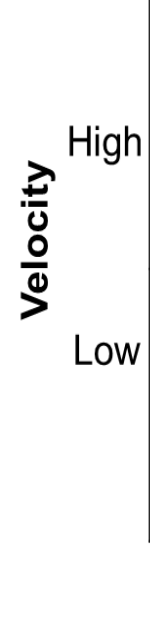 } & $\begin{array}{l}\text { High Velocity, Low Uncertainty } \\
\text { Surgery } \\
\text { Fast Response, Moderate Concern } \\
\text { (IT based escalation increases } \\
\text { response time, but decreases } \\
\text { concerned response time) }\end{array}$ & $\begin{array}{l}\text { High Velocity, High Uncertainty } \\
\text { Cardiac } \\
\text { Fast Response, High Concern } \\
\text { (IT based escalation increases } \\
\text { response time, but decreases } \\
\text { concerned response time) }\end{array}$ \\
\hline & $\begin{array}{l}\text { Low Velocity, Low Uncertainty } \\
\text { Neurology } \\
\text { Slow Response, Least Concern } \\
\text { (IT based escalation decreases } \\
\text { response time, but also decreases } \\
\text { concerned response time) }\end{array}$ & $\begin{array}{l}\text { Low Velocity, High Uncertainty } \\
\text { Oncology } \\
\text { Moderate Response, Moderate Concern } \\
\text { (IT based escalation increases } \\
\text { response time, but no effect on } \\
\text { concerned response time) }\end{array}$ \\
\hline & Low & High \\
\hline
\end{tabular}

Figure 3 - Response, Concern and IT based Escalation for Nurse Calls in Hospital Units 


\section{Implications}

If patient calls come from certain units known to exhibit a set of operating characteristics, then the nurse addressing these patients may follow appropriate protocols built around the expected response behavior. On the other hand, a patient is not privy to these expectations, and any disconnect between these two is exasperated with the introduction of technology. If the technology creates an expectation that is not aligned with the nurse's view of response time adequacy, this disconnect can lead to patient dissatisfaction. Such disconnect may be addressed by creating different layers of response and escalation protocols to calls coming from different units. Can a request from a patient whose call is from a unit viewed as not severe by a nurse be provided options such as alternative messaging to allow the nurse to manage the needed delay while addressing a more pressing need?

A technology that is agnostic to cultural differences in the way nurses and health care providers address a patient call for care may be changing expectations on the patient side, but not on the provider side. This is not necessarily a reflection of a nurse's unwillingness to address a patient need. Rather, the nurse and care delivery team view the call in the context of the type of care (surgical, oncology, etc.) and may be viewing many other care delivery metrics besides patient satisfaction. However, this is not often known to the patient. Therefore, IT enabled call response systems to improve patient satisfaction have to either develop alternative technology/response protocols for requests coming from patients with varying context to address both call efficiency and effectiveness, or adjust the weight of the patient satisfaction metric to reflect these differences.

Transformations enabled by IT are reshaping the behavior of firms and influencing several industry sectors. In particular, transformations brought about and centered on IT implementation have become the core focus of health care organizations in the United States. Several of these implementations have focused on electronic medical records to improve process efficiencies and quality, as well to track costs and reimbursements. However, there has been a recent shift to focus on aligning health care technology (or digitization) with services that create value for patients. This shift in the digitization effort still needs to connect patient care services not to just a single metric such as patient satisfaction, but to a set of core hospital performance measures including cost, quality of care and patient satisfaction, while keeping patients engaged in the care process.

Finally, the findings of this study may be generalized to other IT applications, when the operational attributes contribute to complexity in different dimensions of the decision process. In situations where velocity and uncertainty exist and IT is used in decision support, the "response" and "concerned response" frames referenced in this study become highly relevant. As much as gathering relevant data, and analyzing and presenting multiple options is typical of what IT has been used for in the past, this study makes clear that managers need to take a slightly different approach when considering challenges associated with velocity and uncertainty. When should groups work towards a consensus decision, as in cases where conflicts in interpretations arise, and when should significant differences in interpretation be escalated up to those who have the ultimate responsibility for decision making? When should the decision guidance be left to a single decision maker (e.g. a nurse based on her belief on the immediacy), allowed to be presented to a broader set of stakeholders (e.g. nurses with a certain degree of common expertise), or simply left to the judgement of the highest level of responsibility? 


\section{Contributions}

This study has three contributions for information systems and health management research. First, the study suggests that IT-based systems in health care units need to be evaluated based on their situational embeddedness, given the practice and interpretative variations across different units. While the expectation is that health IT systems will accrue higher value within a health care system, in practice variations may lead the system to have a differentiated impact-that is a unique contribution of this study. Second, the theoretical lens of velocity and uncertainty in operations to explain the unit level variance is a novel contribution. Existing studies have explained unit level variations by other factors than these operational differences. This study explores the potential impact of fit between a performance metric and unit structure. Finally, the study suggests that IT-based escalation of nurse calls may not be effective in answering calls, but when it comes to attending to patients, the impact is quite better. In other words, the study concludes that IT-based systems may not improve efficiency in health care units, but they may be influential in increasing effectiveness. This underlying explanation is the differing impact of efficiency vs effectiveness on health care units, and the trade-offs hospital care units have to make in answering calls.

In addition, this study provides a new frame of reference for IT literature as it is used in decision support - individual or group. Uncertainty and, to some degree, equivocality in the information associated with decision making has led IT to present alternatives for individual decision support, and to gather a richer set of information to highlight conflicts and help seek consensus in group decision making. However, the velocity dimension adds a new degree of complexity. The velocity dimension makes the decision context time variant and complex, and its impact on IT support for decision making is not clear. This study starts to help frame the velocity dimension so that the decision support has to take into consideration an individual's sense making of the context at hand, when they might escalate it to group support, and when there may be a need for human decision making at the highest level of responsibility rather than relying on group consensus. These variations may be somewhat dependent on where the velocity and uncertainty are coming from: data, models used in support of decision process, outputs that have to lead to concerted action, or communication among multiple stakeholders. Future research will try to address some of these dimensional variations on decision support.

\section{Limitations and Future Research}

We acknowledge certain limitations to this study, and these should lead to future opportunities for on-going research. First, our findings are associational due to the use of cross-sectional data, and do not imply causality. There is a need for research in health care units using longitudinal data in order to establish the relationships proposed in this study. Second, while our data focused on hospital unit differences, there is a need to expand the research to different practice levels or hospital levels to explore whether IT-based systems indeed contribute to care effectiveness. A third limitation, and a possible extension of this study, is to validate the findings across other unit contexts for greater generalizability.

\section{Conclusion}

Achieving operational efficiency using ITbased systems is a critical part of the health care transformation. In this study, we investigated how the digitization of patientnurse communication using nurse call systems is improving nurse response times. We argued that patient calls may be responded to differently depending on where they are coming from, as hospital units vary in the way they address uncertainty and velocity. The results from the nurse call system response data from four units in a hospital show that the 
operational variations of these units have an impact on the nurse response times. Also, the escalation protocols that direct calls to a nearest nurse or staff, using a rule-based system, appear to play a mitigating factor in the nurse response times. Further, we suggest that these differences may play a vital role in assessing the impact of nurse call response time on a single metric such as patient satisfaction.

\section{References}

Agid, Y. (2000). "Will Neurological Practice Be Different During the 21st Century?" Archives of Neurology, 57(1), 56-57.

Angkiriwang, R., Pujawan, I. N. and Santosa, B. (2014). "Managing Uncertainty through Supply Chain Flexibility: Reactive vs. Proactive Approaches," Production \& Manufacturing Research, 2(1), 50-70.

Alexander, J. W. and Kroposki, M. (2001). "Using a Management Perspective to Define and Measure Changes in Nursing Technology," Journal of Advanced Nursing, 35(5), 776-783.

Alexander, J. W. and Randolph, W. A. (1985). "The Fit between Technology and Structure as a Predictor of Performance in Nursing Subunits," Academy of Management Journal, 28(4), 844-859.

Argote, L. (1982). "Input Uncertainty and Organizational Coordination in Hospital Emergency Units," Administrative Science Quarterly, 27(3), 420-434.

Bannister, F. and Remenyi, D. (2000). "Acts of Faith: Instinct, Value and IT Investment Decisions", Journal of Information Technology, 15 (3), 231241.

Bardram, J. and Bossen, C. (2005). "Mobility Work: The Spatial Dimension of Collaboration at a Hospital,"
Computer Supported Cooperative Work (CSCW), 14(2), 131-160.

Berg, R. A., Hemphill, R., Abella, B. S., Aufderheide, T. P., Cave, D. M., Hazinski, M. F.,Swor, R. A. (2010). "Part 5: Adult Basic Life Support: 2010 American Heart Association Guidelines for Cardiopulmonary Resuscitation and Emergency Cardiovascular Care," Circulation, 122(18 suppl. 3), S685-S705.

Bowen, M. G. (1987). "The Escalation Phenomenon Reconsidered: Decision Dilemmas or Decision Errors?," The Academy of Management Review, 12 (1), 52-66.

Bourgeois III, L. J. and Eisenhardt, K. M. (1988). "Strategic Decision Processes in High Velocity Environments: Four Cases in the Microcomputer Industry," Management Science, 34(7), 816-835.

Cao, Q., Patterson, J. W. and Bai, X. (2005). "Reexamination of Processing Time Uncertainty," European Journal of Operational Research, 164(1), 185194.

Carlson, J. R. and Zmud, R. W. (1999). "Channel Expansion Theory and the Experiential Nature of Media Richness Perceptions", The Academy of Management Journal, (42)2, 153-170.

Chadwick, A. and Hearn, A. (2014). "A Cry for Help: Time to Re-Think the Patient Call Bell in an Ageing Population," British Journal of Hospital Medicine, 74(11), 642-643.

Chambers, R. G. and Quiggin, J. (2000). Uncertainty, Production, Choice, and Agency: The State-Contingent Approach: Cambridge University Press.

Chulkov, D. V. and Desai, M. S. (2008). "Escalation And Premature Termination in MIS Projects: The Role of Real Options", Information Management \& Computer Security, 16 (4), 324-335 
Currie, V., Harvey, G., West, E., McKenna, $\mathrm{H}$. and Keeney, S. (2005). "Relationship between Quality of Care, Staffing Levels, Skill Mix and Nurse Autonomy: Literature Review," Journal of Advanced Nursing, 51(1), 73-82.

Daft, R. L., Lengel, R. H., and Trevino L. K. (1987). "Message Equivocality, Media Selection, and Manager Performance: Implications for Information Systems", MIS Quarterly, (11)3, 355-366.

Deitrick, L., Bokovoy, J., Stern, G. and Panik, A. (2006). "Dance of the Call Bells: Using Ethnography to Evaluate Patient Satisfaction with Quality of Care," Journal of Nursing Care Quality, 21(4), 316-324.

Deitrick, L. M., Bokovoy, J. and Panik, A. (2010). "The "Dance" Continues... Evaluating Differences in Call Bell Use between Patients in Private Rooms and Patients in Double Rooms Using Ethnography," Journal of Nursing Care Quality, 25(4), 279-287.

Deng, G. E., Frenkel, M., Cohen, L., Cassileth, B. R., Abrams, D. I., Capodice, J. L., $\ldots$ and Kumar, N. (2009). "Evidence-Based Clinical Practice Guidelines for Integrative Oncology: Complementary Therapies and Botanicals," Journal of the Society for Integrative Oncology, 7(3), 85.

Dennis, A. R., Wixom, B. H., and Vandenberg, R. J. (2001). "Understanding Fit and Appropriation Effects in Group Support Systems via Meta-Analysis," MIS Quarterly, 25 (2), 167-193.

Digby, R., Bloomer, M. and Howard, T. (2011). "Improving Call Bell Response Times," Nursing Older People, 23(6), 22-27.

Duncan, R. B. (1972). "Characteristics of Organizational Environments and Perceived Environmental
Uncertainty," Administrative Science Quarterly, 17(3), 313-327.

Ebright, P. (2010). "The Complex Work of RNs: Implications for Healthy Work Environments," Online Journal of Issues in Nursing, 15(1), Online pp.110.

Eisenhardt, K. M. (1989) "Agency theory: An assessment and review." Academy of Management Review, 14(1), 57-74.

Eisenhardt, K. M. and Bourgeois, L. J. (1988). "Politics of Strategic Decision Making in High-Velocity Environments: Toward a Midrange Theory," Academy of Management Journal, 31(4), 737-770.

Endsley, M. R. (1995). "Toward a Theory of Situation Awareness in Dynamic Systems," Human Factors: The Journal of the Human Factors and Ergonomics Society, 37(1), 32-64.

Flin, R., O'Connor, P. and Crichton, M. (2008). "Safety at the Sharp End: Training Non-Technical Skills": Aldershot, England: Ashgate Publishing Ltd.

Frenkel, M., Cohen, L., Peterson, N., Palmer, J. L., Swint, K. and Bruera, E. (2010). "Integrative Medicine Consultation Service in a Comprehensive Cancer Center: Findings and Outcomes," Integrative Cancer Therapies, 9(3), 276-283.

Fry, L. W. and Slocum, J. W. (1984). "Technology, Structure, and Workgroup Effectiveness: A Test of a Contingency Model," Academy of Management Journal, 27(2), 221-246.

Fuller, R. and Dennis, A. (2009). "Does Fit matter? The Impact of TaskTechnology Fit and Appropriation on Team Performance in Repeated Tasks," Information Systems Research, 20(1), 2-17.

Galinato, J., Montie, M., Patak, L. and Titler, M. (2015). "Perspectives of Nurses 
and Patients on Call Light Technology," Computers Informatics Nursing, 33(8), 359-367.

Gilboa, I. (2009). Theory of Decision under Uncertainty (Vol. 1): Cambridge University Press, Cambridge.

Goodhue, D. L., and Thompson, R. L. (1995). "Task-technology Fit and Individual Performance", MIS Quarterly, 19 (2), 213-236.

Greene, W. H. (2008). Econometric Analysis: Pearson/Prentice Hall. Irani, Z., Sharif, A. M. and Love, P. E. D. (2005). "Linking Knowledge Transformation to Information Systems Evaluation," European Journal of Information Systems, 14 (3), 213-228.

Khuntia, J., Tanniru, M. and Weiner, J. (2015). "Juggling Digitization and Technostress: The Case of Alert Fatigues in the Patient Care System Implementation," Health Policy and Technology, Online (August).

Klemets, J. and Evjemo, T. E. (2014). "Technology-MediatedAwareness:

Facilitating the Handling of (Un) Wanted Interruptions in a Hospital Setting," International Journal of Medical Informatics, 83(9), 670-682.

Klemets, J., Evjemo, T. E. and Kristiansen, L. (2012). "Designing for Redundancy: Nurses Experiences with the Wireless Nurse Call System," Studies in Health Technology and Informatics, 192(1), 328-332.

Koroshetz, W. J. and Landis, S. (2014). "Neurology's Stake in Foundational Neuroscience Research," JAMA Neurology, 71(9), 1081-1082.

Lasiter, S. (2014). "“The Button" Initiating the Patient-Nurse Interaction," Clinical Nursing Research, 23(2), 188200.

Leatt, P. and Schneck, R. (1981). "Nursing Subunit Technology: A Replication,"
Administrative Science Quarterly, 225-236.

Leatt, P. and Schneck, R. (1982). "Technology, Size, Environment, and Structure in Nursing Subunits," Organization Studies, 3(3), 221-242.

Lee, J. Y. H. and Panteli, N. (2010) "Business Strategic Conflict in Computer-Mediated Communication", European Journal of Information Systems, (19)2, 196-208.

Lengel, R. H. and Daft, R. L. (1989). "The Select ion of Communication Media as an Executive Skill", The Academy of Management Executive, (2)3, 225232.

Meade, C. M., Bursell, A. L. and Ketelsen, L. (2006). "Effects of Nursing Rounds: On Patients' Call Light Use, Satisfaction, and Safety," The American Journal of Nursing, 106(9), 58-70.

Miles, R. E., Snow, C. C., Meyer, A. D. and Coleman, H. J. (1978). "Organizational Strategy, Structure, and Process," Academy of Management Review, 3(3), 546-562.

Milliken, F. J. (1987). "Three Types of Perceived Uncertainty About the Environment: State, Effect, and Response Uncertainty," Academy of Management Review, 12(1), 133-143

Overton, P., Schneck, R. and Hazlett, C. B. (1977). "An Empirical Study of the Technology of Nursing Subunits," Administrative Science Quarterly, 22(2), 203-219.

Prgomet, M., Georgiou, A. and Westbrook, J. I. (2009). "The Impact of Mobile Handheld Technology on Hospital Physicians' Work Practices and Patient Care: A Systematic Review," Journal of the American Medical Informatics Association, 16(6), 792801. 
Reason, J. (2001). "Understanding Adverse Events: The Human Factor (P. 9-30)," Vincent C. Clinical Risk Management: Enhancing Patient Safety. London: BMJ Books.

Ren, Y., Kiesler, S. and Fussell, S. R. (2008). "Multiple Group Coordination in Complex and Dynamic Task Environments: Interruptions, Coping Mechanisms, and Technology Recommendations," Journal of Management Information Systems, 25(1), 105-130.

Robert, L. P. and Dennis A.R. (2005). "Paradox of Richness: A Cognitive Model of Media Choice", IEEE Transactions on Professional Communication, (48)1, 10-21.

Roger, V. L., Go, A. S., Lloyd-Jones, D. M., Benjamin, E. J., Berry, J. D., Borden, W. B., . . Turner, M. B. (2012). "Heart Disease and Stroke Statistics-2012 Update: A Report from the American Heart Association," Circulation, 125(1), e2-e220.

Roszell, S., Jones, C. B. and Lynn, M. R. (2009). "Call Bell Requests, Call Bell Response Time, and Patient Satisfaction," Journal of Nursing Care Quality, 24(1), 69-75.

Schmidt, K. (2002). "The Problem Withawareness': Introductory Remarks on Awareness in CSCW'," Computer Supported Cooperative Work, 11(3-4), 285-298.

Schmitt, A. J. and Snyder, L. V. (2012). "Infinite-Horizon Models for Inventory Control under Yield Uncertainty and Disruptions," Computers \& Operations Research, 39(4), 850-862.

Schoonhoven, C. B. (1981). "Problems with Contingency Theory: Testing Assumptions Hidden within the Language of Contingency" Theory"," Administrative Science Quarterly, 349-377.
Sheedy, S. (1989). "Responding to Patients-the Unit Hostess," Journal of Nursing Administration, 19(4), 31-33.

Smithson, S. and Hirschheim, R. (1998). "Analysing Information Systems Evaluation: Another Look at an Old Problem", European Journal of Information Systems, 7 (3), 158-174.

Smits, M., Groenewegen, P. P., Timmermans, D. R., van der Wal, G. and Wagner, C. (2009). "The Nature and Causes of Unintended Events Reported at Ten Emergency Departments," BMC Emergency Medicine, 9(1), 16-22.

Stüve, O. (2012). "The Cradle of American Neurology: The Harvard Neurological Unit at the Boston City Hospital," Archives of Neurology, 69(10), 13781379.

doi:10.1001/archneurol.2012.1822

Tang, C. S. (2006). "Perspectives in Supply Chain Risk Management," International Journal of Production Economics, 103(2), 451-488.

Timmerman, C. E. and Madhavapeddi, S. N. (2008) "Perceptions of Organizational Media Richness: Channel Expansion Effects for Electronic and Traditional Media across Richness Dimensions", IEEE Transactions on Professional Communication, 51(1), 18- 32.

Tiwana, A., Keil, M. and Fichman, R. G. (2006). "Information Systems Project Continuation in Escalation Situations: A Real Options Model," Decision Sciences, 37(3), 357-391.

Torres, S. M. (2007). "Rapid-Cycle Process Reduces Patient Call Bell Use, Improves Patient Satisfaction, and Anticipates Patient's Needs," Journal of Nursing Administration, 37(11), 480-482.

Toussaint, P. J. and Coiera, E. (2005). "Supporting Communication in Health Care," International Journal of Medical Informatics, 74(10), 779-781. 
Tzeng, H.-M. (2010). "Perspectives of Staff Nurses of the Reasons for and the Nature of Patient-Initiated Call Lights: An Exploratory Survey Study in Four USA Hospitals," BMC Health Services Research, 10(1), 52.

Tzeng, H.-M. (2011). "Perspectives of Staff Nurses toward Patient-and FamilyInitiated Call Light Usage and Response Time to Call Lights," Applied Nursing Research, 24(1), 5963.

Tzeng, H. M. and Yin, C. Y. (2009a). "Are Call Light Use and Response Time Correlated with Inpatient Falls and Inpatient Dissatisfaction?," Journal Of Nursing Care Quality, 24(3), 232-242.

Tzeng, H. M. and Yin, C. Y. (2009b). "Relationship between Call Light Use and Response Time and Inpatient Falls in Acute Care Settings," Journal of Clinical Nursing, 18(23), 3333-3341.

Van Handel, K. and Krug, B. (1994). "Prevalence and Nature of Call Light Requests on an Orthopaedic Unit," Orthopaedic Nursing, 13(1), 13-18.

Van Kampen, T. J., Van Donk, D. P. and Van Der Zee, D.-J. (2010). "Safety Stock or Safety Lead Time: Coping with Unreliability in Demand and Supply," International Journal of
Production Research, 48(24), 74637481.

Watson-Manheim, M. B. F. and Bélanger, F. (2007). "Communication Media Repertoires: Dealing with the Multiplicity of Media Choices", MIS Quarterly, 31(2), 267-293.

Weick, K. E., Sutcliffe, K. M. and Obstfeld, D. (2005). "Organizing and the Process of Sensemaking," Organization science, 16(4), 409-421.

Wu, T., Blackhurst, J. and O'grady, P. (2007). "Methodology for Supply Chain Disruption Analysis," International Journal of Production Research, 45(7), 1665-1682.

Yancy, C. W., Jessup, M., Bozkurt, B., Butler, J., Casey, D. E., Drazner, M. H., ... and Wilkoff, B. L. (2013). "2013 Accf/Aha Guideline for the Management of Heart Failure: A Report of the American College of Cardiology Foundation/American Heart Association Task Force on Practice Guidelines," Circulation, 128(16), e240-e327.

Zinn, J. S., Brannon, D., Mor, V. and Barry, T. (2003). "A Structure-Technology Contingency Analysis of Caregiving in Nursing Facilities," Health Care Management Review, 28(4), 293-306. 


\section{Appendix A: Data Collection, Analysis and Interpretation}

Table A1 - Analysis of Comments from allnurses.com in support of the unit differences

\begin{tabular}{|c|c|c|c|}
\hline 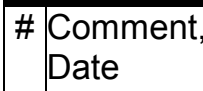 & User ID & Quote & Classification \\
\hline \multicolumn{4}{|c|}{ Nurse Discussions and Comments in Surgery Practice } \\
\hline \begin{tabular}{l|l}
7 & $7 \mathrm{Apr}$ \\
2012
\end{tabular} & RN22, BSN, RN & $\begin{array}{l}\text { "... I worked in prep/pacu for some time. It was very routine } \\
\text { and fast - I eventually became bored of the mundane } \\
\text { work." }\end{array}$ & $\begin{array}{l}\text { High velocity, } \\
\text { low uncertainty }\end{array}$ \\
\hline $2 \begin{array}{l}8 \text { Mar } \\
2009\end{array}$ & thenightnurse 456 & "...Patients can go south very fast in Onc...” & High velocity \\
\hline \begin{tabular}{l|l}
3 & $25 \mathrm{Apr}$ \\
2011
\end{tabular} & DatMurse, BSN & $\begin{array}{l}\text { "How much does patient care vary form this to a strict } \\
\text { heme onc floor.. I am sitting there wondering if my patient } \\
\text { will go south real fast." }\end{array}$ & High velocity \\
\hline \begin{tabular}{l|l}
$9 \mathrm{Mar}$ \\
2009
\end{tabular} & EricJRN & $\begin{array}{l}\text { "“...It seems like you're having uncertainty about treatment } \\
\text { options...but it is not that important..." }\end{array}$ & Uncertainty \\
\hline \begin{tabular}{l|l}
5 & 20 Feb \\
2010
\end{tabular} & MollyJ, MSN, RN & $\begin{array}{l}\text { ".......hey are coping with uncertainty.. cope with all of } \\
\text { that with amazing grace and class; others do not." }\end{array}$ & Low uncertainty \\
\hline \multicolumn{4}{|c|}{ Nurse Discussions and Comments in Cardiology Practice } \\
\hline \begin{tabular}{l|l}
1 & 16 Nov \\
2012
\end{tabular} & Lilu86, BSN & $\begin{array}{l}\text { "The nurse manager told me right off the bat that this was } \\
\text { a very paced unit. This worries me, because fast paced } \\
\text { doesn't really suite me well." }\end{array}$ & High velocity \\
\hline \begin{tabular}{l|l}
2 & 12 Oct \\
2012
\end{tabular} & Seas, MSN & $\begin{array}{l}\text { "I am not the only one in my unit who feel stressed to the } \\
\text { max just for coming into work that is so much rapid and } \\
\text { uncertain" }\end{array}$ & $\begin{array}{l}\text { High velocity, } \\
\text { high uncertainty }\end{array}$ \\
\hline \begin{tabular}{l|l}
3 & $21 \mathrm{Nov}$ \\
2012
\end{tabular} & m1ckey & $\begin{array}{l}\text { "working on a med-surg cardiac unit and I absolutely love } \\
\text { it! Just take everything in step by step and BREATHE. It's } \\
\text { a lot quick to take in but everything will make sense. Also, } \\
\text { ASK QUESTIONS." }\end{array}$ & High velocity \\
\hline \begin{tabular}{l|l}
4 & $11 \mathrm{Dec}$ \\
2010
\end{tabular} & NYLady & $\begin{array}{l}\text { "If you didn't have much related experience before you } \\
\text { started the job that could explain your uncertainty but I } \\
\text { would expect you to start feeling comfortable with most } \\
\text { aspects of the job by now." }\end{array}$ & High uncertainty \\
\hline \begin{tabular}{l|l|}
5 & 30 March \\
2014
\end{tabular} & $\begin{array}{l}\text { GrnTea, BSN, } \\
\text { MSN, RN }\end{array}$ & $\begin{array}{l}\text { "...Related factors do include, "uncertainty of prognosis," } \\
\text { so now to complete your diagnostic statement ..." }\end{array}$ & High uncertainty \\
\hline \multicolumn{4}{|c|}{ Nurse Discussions and Comments in Oncology Practice } \\
\hline $1 \mid$\begin{tabular}{l|l}
$8 \mathrm{Apr}$ \\
2013
\end{tabular} & $\begin{array}{l}\text { 81Bubbles, ADN, } \\
\text { RN }\end{array}$ & $\begin{array}{l}\text { "pace usually slower and you might have a larger patient } \\
\text { load than during day shift." }\end{array}$ & Low velocity \\
\hline \begin{tabular}{l|l}
$8 \mathrm{Mar}$ \\
2009
\end{tabular} & $\begin{array}{l}\text { NewYorkerGirl, } \\
\text { BSN, RN }\end{array}$ & $\begin{array}{l}\text { "I had a professor in nursing school who said working } \\
\text { oncology nursing at a cancer center was slow-paced." }\end{array}$ & Low velocity \\
\hline \begin{tabular}{l|l}
3 & 13 Jan \\
& 2014
\end{tabular} & $\begin{array}{l}\text { SoldierNurse22, } \\
\text { BSN, RN, EMT-B }\end{array}$ & $\begin{array}{l}\text { "I had no say in the matter but benefitted greatly from the } \\
\text { experience, despite the uncertainty." }\end{array}$ & High uncertainty \\
\hline \begin{tabular}{l|l}
4 & 20 Feb \\
2001
\end{tabular} & MollyJ, MSN, RN & $\begin{array}{l}\text { "They are coping with uncertainty, seeing their child in } \\
\text { pain, death anxiety etc" }\end{array}$ & High uncertainty \\
\hline
\end{tabular}




\begin{tabular}{|c|c|c|c|}
\hline $\begin{array}{l}1 \\
7 \mathrm{Mar} \\
2011\end{array}$ & AntMarchingRN & $\begin{array}{l}\text { "I went to work in a neurology unit thinking I could use my } \\
\text { rn and psych degrees together in a great scenario. I } \\
\text { lasted } 5 \text { months. I was bored ... if you like the slow pace, } \\
\text { it may be for you." }\end{array}$ & Low velocity \\
\hline $\begin{array}{l}23 \text { Mar } \\
2010\end{array}$ & shortsuzy87 & $\begin{array}{l}\text { "even told me the pace would be slower than what I'm } \\
\text { used to... so I could explain to them a calmer pace is } \\
\text { exactly what I'm looking for." }\end{array}$ & Low velocity \\
\hline \begin{tabular}{l|l}
3 & 7 July \\
2015
\end{tabular} & $\begin{array}{l}\text { Here.I.Stand, } \\
\text { BSN, RN }\end{array}$ & $\begin{array}{l}\text { "I love the challenge and certainty of it. I like being on high } \\
\text { alert. And when an outcome is favorable, it's amazing to } \\
\text { see." }\end{array}$ & ncertainty \\
\hline $\begin{array}{l}426 \text { Sep } \\
2008\end{array}$ & Cfitz & $\begin{array}{l}\text { “... enormous amount of guilt, but peaceful, predictable. } \\
\text { Why can't I hack it? Why can't I just deal with it?” }\end{array}$ & Low uncertainty \\
\hline \begin{tabular}{l|l}
5 & 20 Feb \\
2010
\end{tabular} & MollyJ, MSN, RN & $\begin{array}{l}\text { ".......hey are coping with uncertainty.. cope with all of } \\
\text { that with amazing grace and class; others do not." }\end{array}$ & Low uncertainty \\
\hline
\end{tabular}

\section{Appendix B: Additional Illustrations}

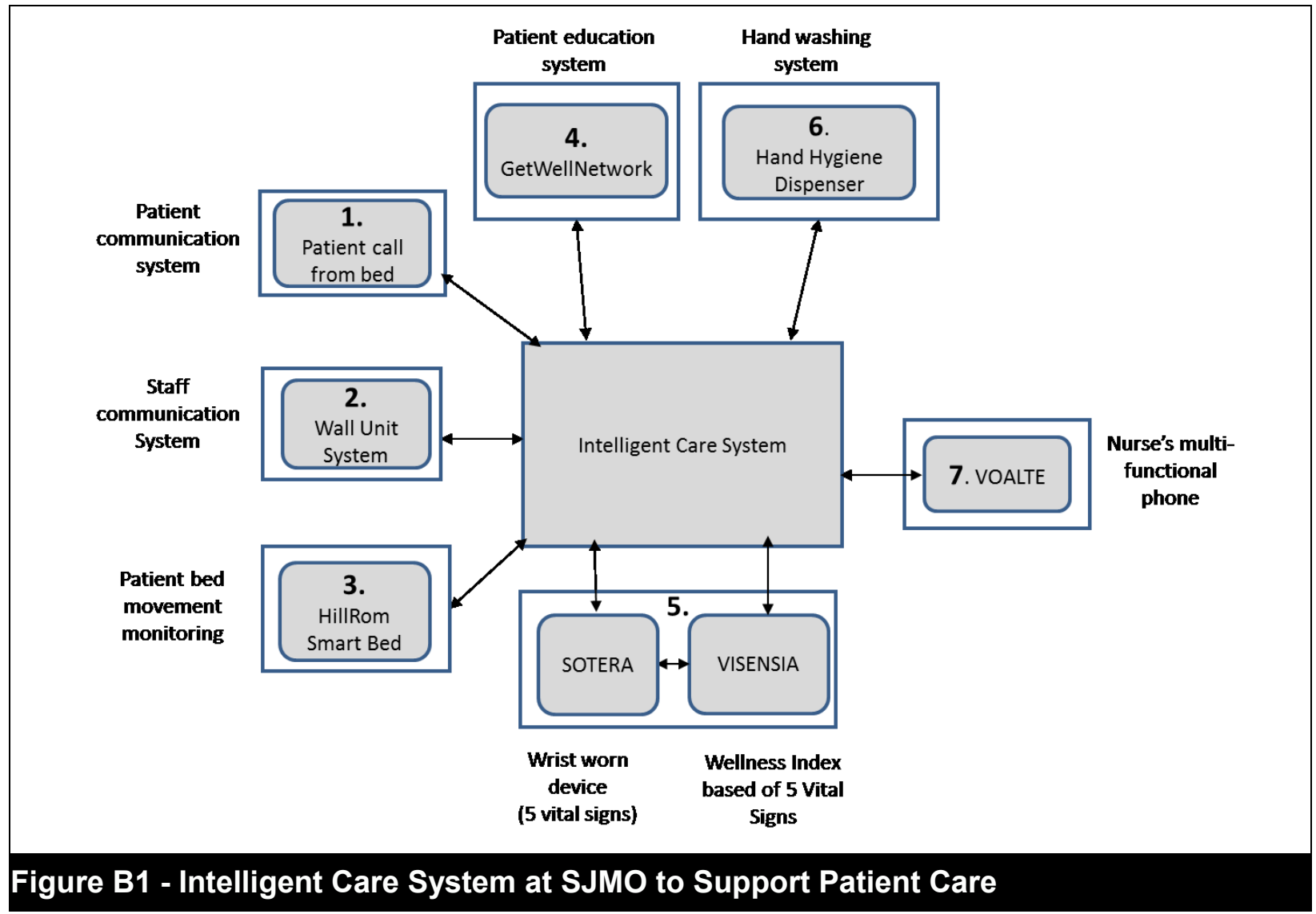




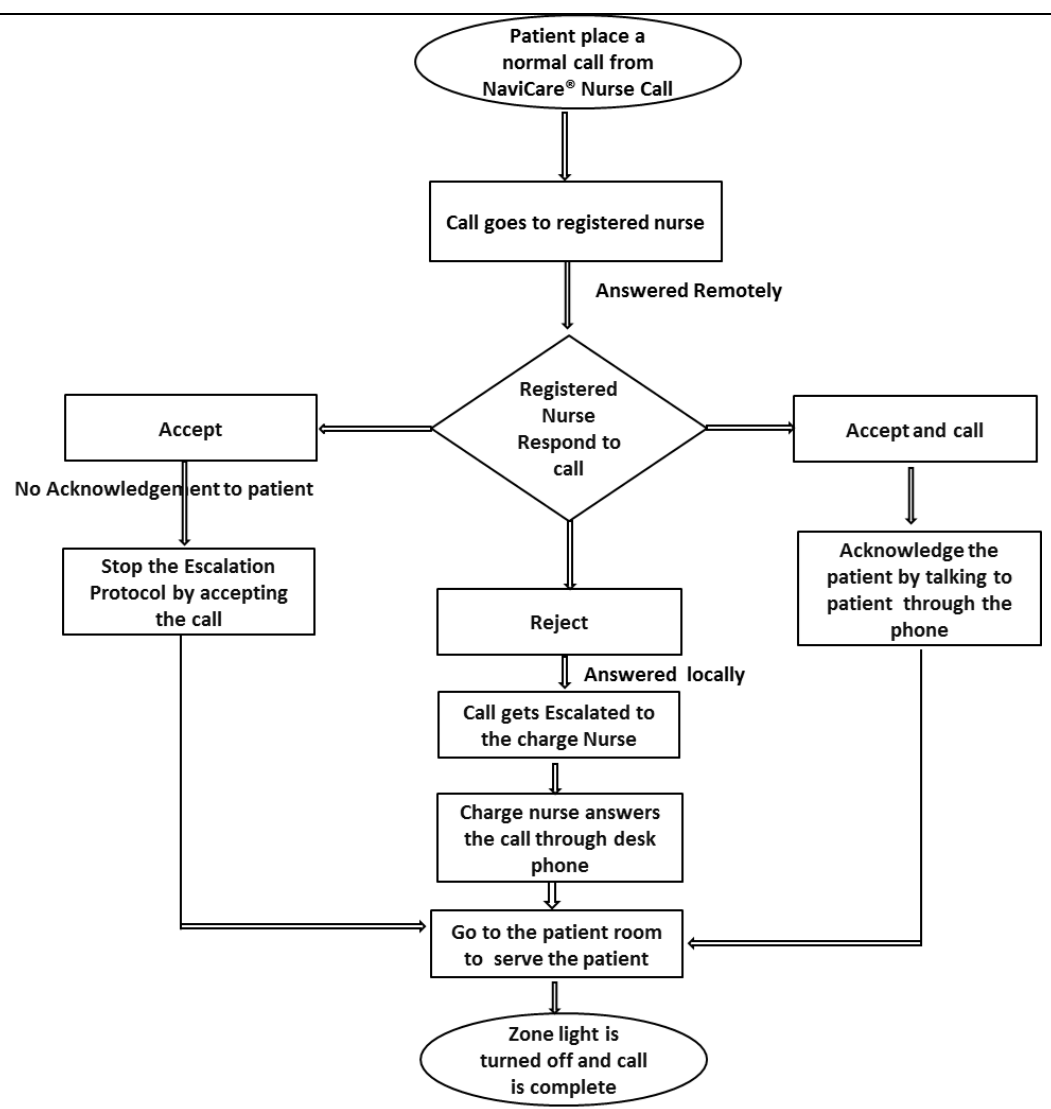

\section{Figure B2 - Normal Nurse Call System and Response Flow}

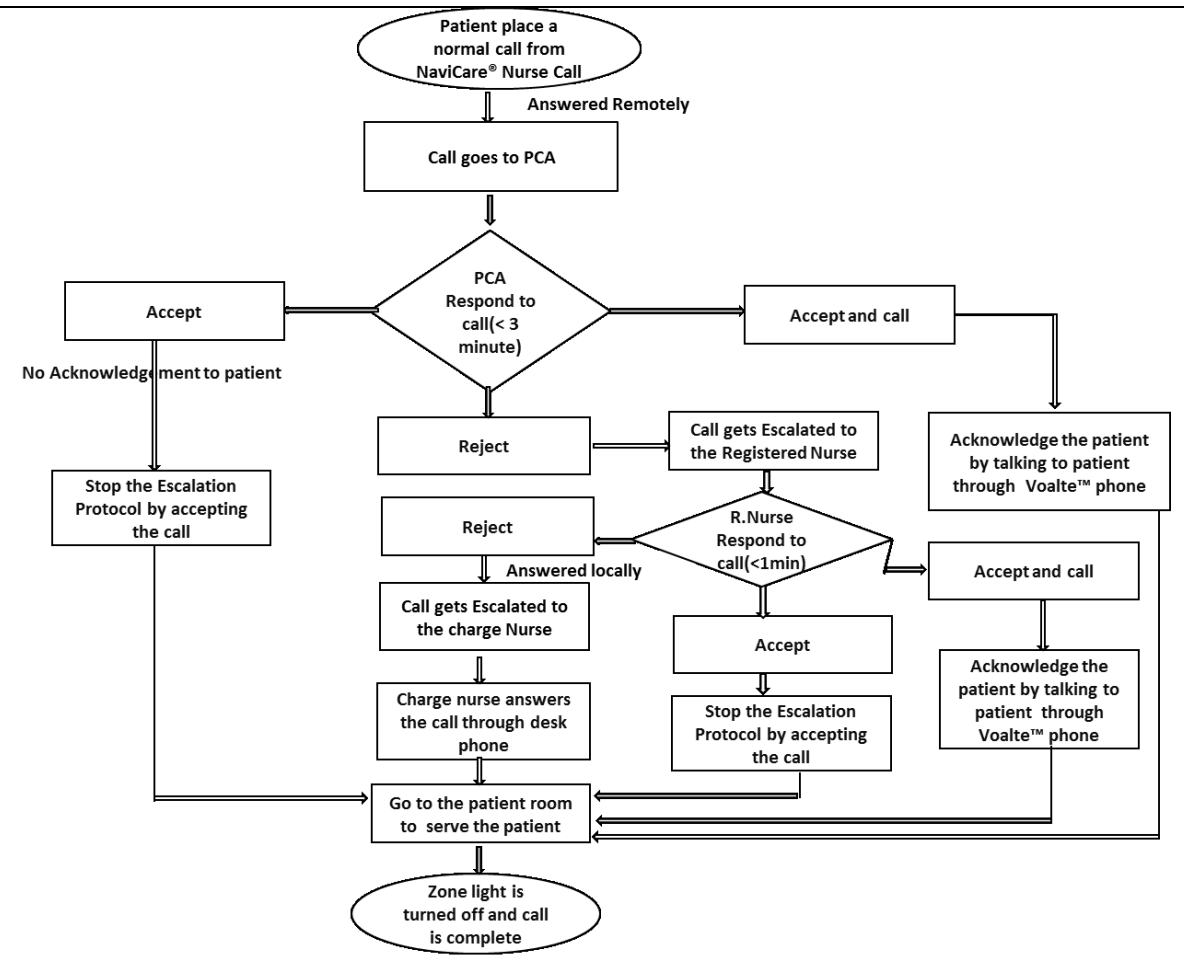

Figure B3 - Nurse Call System and Response Flow with the Toilet Calls 


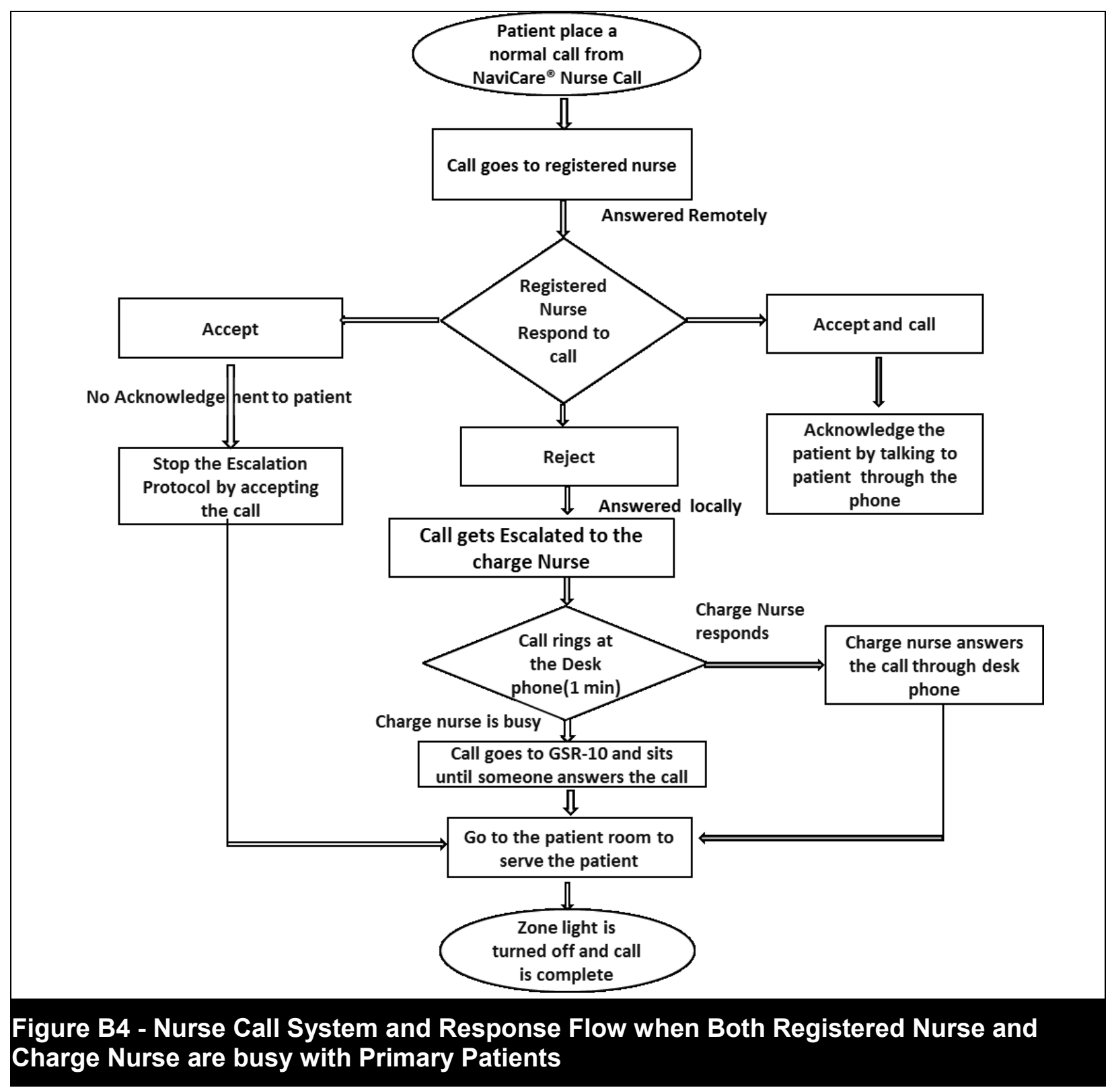

\section{About the Authors}

Dr. Jiban Khuntia is an assistant professor in the Business School at University of Colorado, Denver. His research is in the areas of digital service innovation and digital health. His work has appeared in journals including Decision Support Systems, Communications of the Association for Information Systems, Health Policy and Technology and International Journal of EBusiness Research. He received his PhD from University of Maryland, College Park in 2013.

Dr. Mohan Tanniru is the Professor of MIS at Oakland University. His research interests are in the areas of IT strategy, decision and knowledge based support and health care service delivery innovations. He authored over 75 articles in journals and books including ISR, MIS Quarterly, Decision Sciences, DSS, JMIS, IEEE Transactions in Eng. Management, Information and Management and 
IS Impact on Nurse Call Response / Khuntia et al.

Communications of ACM. He held the positions as the Dean of Business School at Oakland University, Head of the MIS Dept. at the $U$ of Arizona and taught at $\mathrm{OU}$, Syracuse and UW-Madison. He received his Ph.D. from Northwestern University in 1978.

Fabian Fregoli, MD, is Vice President of Quality and Patient Safety at St. Joseph Mercy Oakland (SJMO) and Regional Chief Medical Informatics Officer-East Market for the Saint Joseph Mercy Health System. He is board certified by the American Board of Family Medicine. In addition to his focus on clinical quality and patient safety, Dr. Fregoli provides leadership in the area of clinical informatics to SJMO and St. Mary
Mercy Livonia hospitals. Dr. Fregoli completed his residency in Family Medicine at William Beaumont Hospital-Grosse Pointe.

Matthew Nawrocki is a Database Administrator and Business Intelligence Developer for St. Joseph Mercy Oakland. He graduated with a B.S.from the University of Michigan, Ann Arbor, and an M.B.A., specializing in MIS, from Oakland University. His work involves business analytics, architecture and development of software solutions, and technological implementations to improve operational processes and evidenced-based discovery. 